\title{
The Macroeconomic Effects of Income and Consumption Tax Changes
}

\author{
Document Version \\ Accepted author manuscript
}

Link to publication record in Manchester Research Explorer

\section{Citation for published version (APA):}

Nguyen, A., Onnis, L., \& Rossi, R. (2020). The Macroeconomic Effects of Income and Consumption Tax Changes. American Economic Journal: Economic Policy, 0, 0. [0].

https://www.aeaweb.org/articles?id=10.1257/pol.20170241\&\&from=f

\section{Published in:}

American Economic Journal: Economic Policy

\section{Citing this paper}

Please note that where the full-text provided on Manchester Research Explorer is the Author Accepted Manuscript or Proof version this may differ from the final Published version. If citing, it is advised that you check and use the publisher's definitive version.

\section{General rights}

Copyright and moral rights for the publications made accessible in the Research Explorer are retained by the authors and/or other copyright owners and it is a condition of accessing publications that users recognise and abide by the legal requirements associated with these rights.

\section{Takedown policy}

If you believe that this document breaches copyright please refer to the University of Manchester's Takedown Procedures [http://man.ac.uk/04Y6Bo] or contact uml.scholarlycommunications@manchester.ac.uk providing relevant details, so we can investigate your claim.

\section{OPEN ACCESS}




\title{
The Macroeconomic Effects of Income and Consumption Tax Changes
}

\author{
By Anh D.M. Nguyen, Luisanna Onnis and Raffaele Rossi *
}

This paper estimates the effects of exogenous changes in income and consumption taxes. The tax shocks are proxied with a narrative account of tax liability changes in the United Kingdom. Income tax cuts have large effects on GDP, private consumption and investment. The effects of consumption tax cuts are modest and not statistically significant on GDP and its components. Shifting the burden of taxation from income to consumption is expansionary. Consistent with conventional public finance theories, these results indicate that it is crucial to distinguish between direct and indirect taxation when studying the transmission mechanism of fiscal policy.

\section{Introduction}

Do consumption and income tax changes affect economic aggregates such as income, private consumption and investment differently? The answer to this ageold question is central for the setting of economic policy and its role in pursuing economic stabilisation, efficiency and growth.

Conventional public finance theories argue that consumption taxes are less distortive than income taxes, see Summers (1981), Auerbach, Kotlikoff and Skinner (1983), Jones, Manuelli and Rossi (1993) and Trabandt and Uhlig (2011) amongst others. From this, two main theoretical results emerge: i) income tax multipliers are larger than consumption tax multipliers (Fernández-Villaverde, 2010; and Sims and Wolff, 2018 amongst others) and ii) changing the composition of fiscal revenues by shifting the burden of taxation from income to consumption is expansionary (Coleman, 2000; Altig et al., 2001; and Correia, 2010 amongst others). ${ }^{1}$

\footnotetext{
* Nguyen: Economics Department, Bank of Lithuania and Faculty of Economics and Business Administration, Vilnius University, Lithuania. Email: anguyen@1b.lt. Onnis: Department of Accountancy, Finance and Economics, University of Huddersfield, HD1 3DH, United Kingdom. Email: 1.onnis@hud.ac.uk. Rossi: Department of Economics, University of Manchester, M13 9PL, United Kingdom. Email: raffaele.rossi@manchester.ac.uk. Acknowledgements: We are grateful to Matthew Shapiro (the Editor), an anonymous referee and James Cloyne for detailed suggestions and useful comments. We also thank James Banks, Paul Beaudry, John Cochrane, Alaistar Hall, Sarolta Laczó, Giorgio Motta, Roberto Pancrazi, Ivan Petrella, Myroslav Pidkuyko, Michele Piffer, Silvana Tenreyro, Akos Valentinyi, Eugenia Vella, Mazhar Waseem, Matthias Weber and the participants at various seminars and conferences for useful comments. Rossi also acknowledges the School of Social Sciences at Manchester University for funding part of this project. The views expressed in this paper are not those of the Bank of Lithuania or the Eurosystem.

${ }^{1}$ In general, a consumption tax cut induces a relative price effect as investment becomes relatively more expansive than consumption. This substitution effect reduces saving in equilibrium, thus dampening
} 
However, despite considerable research in the theoretical literature, little is known from an empirical perspective about the joint macroeconomic effects of changes in income taxes as opposed to changes in consumption taxes. Our main contribution consists in providing new estimates of these effects. As such, the goal of the paper is twofold: i) estimating the relative merits of consumption and income tax changes on aggregate macro-variables; and ii) estimating the effects of changing the composition of the tax burden from income to consumption. We identify exogenous tax changes in a vector autoregressive model (VAR) by proxying the latent tax shocks with a narrative measure of consumption and income tax liabilities changes for the United Kingdom, over the period 1973-2009.

We find that unexpected changes in average income tax rates (AITR), defined as an aggregate of personal and corporate taxes, have large short run effects on GDP, private consumption and investment. In our benchmark model, a percentage point cut in AITR raises GDP on impact by 0.78 percent, and leads to maximal present value multipliers of 2.36 percent two years after the shock. We also show that AITR cuts 'Starve the Beast', i.e. government spending shrinks in response to income tax decreases.

Differently, the effects of cuts in average consumption tax rates (ACTR), e.g. VAT and consumption duties, are modest and not significantly different than zero on GDP and its components. We also show that shifts in the composition of the tax burden from income to consumption are expansionary: revenue neutral policies that increase consumption taxes and decrease income taxes, have a significant expansionary effect on GDP. In this respect, our estimates confirm the theoretical predictions on the effects of income and consumption tax changes.

On the policy side, our findings provide empirical insights about the fiscal reforms and the ongoing proposals aimed to shift the burden of taxation from income to consumption. During the period 1979-1997, UK governments legislated several policy changes where cuts of income based taxes were coupled with increases in consumption taxes. As such, the composition of tax revenues moved considerably from income to consumption. Starting from 1976 and up until 1997 the share of total fiscal revenues due to income tax, decreased from 70 percent to 55 percent, while the share of revenues coming from consumption tax increased from 15 percent to 35 percent. The shift in the composition of taxes was only partially reversed after 1997. All in all, analysing the relative merits of income and consumption tax and the effects of changing the composition of tax revenues is not only an intuitive way to test standard public finance theories, but it is also useful in practice to understand the UK in this period.

Measuring the effects of a tax change is particularly challenging for (at least)

the multiplier effect on GDP of consumption taxes. Under income tax the relative price effect is absent or greatly reduced. Moreover, for a given level fiscal revenues, the consumption tax combines a one-time, non-distortionary lump-sum on part of the initial level of wealth, with an income tax. Since income tax itself is distortionary, it is natural to expect that the wealth effect of a cut in consumption tax to be smaller than the one implied by a cut in income tax. As a result income tax multipliers are larger than consumption tax multipliers. See the Online Appendix for a general equilibrium model that formalises these effects. 
three reasons. First of all, there is a well known problem of endogeneity, as fiscal policy is rarely the result of random experimentation. Tax changes are likely to contemporaneously affect various expenditure components of GDP. At the same time, tax changes are also contemporaneously driven by GDP and its components. Second, distinct tax instruments are likely to affect the economy through separate channels, and hence lead to important differences in the transmission mechanism of fiscal policy, particularly when compared to an aggregate measure of tax changes. Third, changes in different tax components often happen at the same time as part of articulated and complex fiscal reforms. This is particularly true for the UK where in the period under consideration, income and consumption tax changes were very often legislated jointly. Partly due to these difficulties, existing empirical estimates of tax multipliers vary greatly.

First, we deal with the endogeneity issue through an identification strategy that exploits selected legislated tax changes as 'proxies' for the latent tax shocks in a Structural VAR model, e.g. Proxy-SVAR, see Mertens and Ravn (2013, 2014), Caldara and Kamps (2017) and Stock and Watson (2018). This identification strategy relies on assuming that narrative measures of exogenous policy changes correlate with latent tax shocks but are orthogonal to other structural shocks. The advantage of this method is that it exploits the rich information set behind the narrative accounts but it is robust to potential measurement errors (typically present in narrative dataset) as it does not require perfect correlation between the narrative measures and the latent structural tax shocks. At the same time, it avoids any identifying assumption for the key structural elasticities. In turn, these elasticities are directly estimated within the econometric model.

Second, in order to isolate the effects of different tax components, we present a narrative measure of consumption and income tax changes in the UK. Our dataset is constructed by using Cloyne $(2012,2013 a)$ 's account of changes in total tax liabilities that we organise into changes in consumption (VAT and other consumption duties) and income (personal and corporate) tax liabilities. We only use tax changes that are classified as 'exogenous', i.e. decisions that were taken for reasons uncorrelated with macroeconomic conditions. Our narrative dataset contains valuable information about the latent structural tax shocks and is exogenous to the remaining structural shocks. As such, we use these narrative measures as proxies for the latent structural tax shocks in a SVAR model.

Of course it would be best to study the effects of changes in the most narrowly defined tax components. However, there are practical limits to the level of disaggregation given by data availability. For instance, we cannot distinguish between personal vs. corporate tax changes. Nevertheless, our categorisation of income vs. consumption tax has a clear theoretical counterpart and, at the same time, it allows to calculate tax rates via consistent data on fiscal revenues on the sample under consideration.

Third, we need to deal with the correlation between income and consumption tax changes. The simple observation that many tax changes happened as part 
of large and complex fiscal reforms suggests that we need a joint identification scheme for the shocks in these two tax components. As such, we cannot impose that the proxy for one tax shock is orthogonal to the other tax shock, as the narrative liability changes in one tax component could potentially contain valuable information also about the other tax component.

We deal with this issue by using two complementary identification procedures. In our benchmark, we use a traditional recursive identification, i.e. Cholesky, which imposes a timing assumption, whereas a shock in one tax component leaves the other tax component unchanged on impact, see Mertens and Ravn (2013) and Caldara and Kamps (2017). Then we propose an alternative approach that uses a sign restriction scheme in the same fashion of Peersman (2005) and Piffer and Podstawski (2017) (see also Nevo and Rosen, 2012) where we impose that tax shocks in one tax component correlate more, on impact, with variations in the corresponding tax rate. For example, shocks to income tax rates have a bigger effect on impact on AITR than on ACTR. This setup uses rather agnostic restrictions on the correlation structure between the shocks and the proxies as it does not impose zero restrictions in the impulse responses. In this way we achieve set-identification with a minimal set of assumptions. Most importantly, our results are largely similar under the two identification schemes.

Related Literature. - This paper mostly relates to the literature on tax multipliers. Earlier contributions in this literature mainly studied the effects of aggregate tax shocks, e.g. Blanchard and Perotti (2002), Mountford and Uhlig (2009), Romer and Romer (2010), Favero and Giavazzi (2012) and Cloyne (2013a). Nevertheless, as we show here, distinct tax components are likely to affect the economy through separate channels, and hence lead to important differences in the transmission mechanism of fiscal policy. These insights are generally missed in analyses with aggregate tax shocks.

A more recent literature studies the transmission mechanism of income tax components and finds, like in our paper, that indicators of real activity, such as GDP, investment, and employment, respond significantly to changes in income taxes, e.g. Barro and Redlick (2011), Cloyne and Surico (2017), Mertens and Montiel-Olea (2018), and Zidar (2018). The closest contribution to our paper can be found in Mertens and Ravn (2013) who analyse separately the impact of personal vs. corporate tax changes in the US economy (see also Hussain and Liu, 2018 for a similar analysis on UK data). They find that both tax components have large short-run effects on GDP and investment, while they document a different transmission mechanism on private consumption and the labour market. However Mertens and Ravn (2013) focus on two homogeneous tax categories of income, i.e. both personal and corporate taxes are part of direct taxation. Differently, we concentrate on the comparison between direct (AITR) and indirect (ACTR) taxation and on the effects of changing the composition of total fiscal revenues between these two tax components. 
Along the same line, our paper is also closely related to Riera-Crichton, Vegh and Vuletin (2016), who adopt a narrative approach to estimate the effects of VAT changes for fiscal consolidation purposes in a panel of fourteen countries and find that shocks to this tax component have large and significant expansionary effects on GDP. Riera-Crichton, Vegh and Vuletin (2016) analysis comprises only of exogenous VAT changes, thus they do not control for potential contemporaneous exogenous changes in other tax components. This is mostly due to data limitation. We show that we can obtain large ACTR multipliers by ignoring the observed correlation between exogenous movements in consumption and income taxes. We conclude that controlling for simultaneous changes in income taxes appears crucial for a correct evaluation of the transmission mechanism of consumption taxation.

The rest of this paper is organised as follows. Section II describes the empirical model. Section III presents the narrative dataset used for identification as well as a brief historical background of the underlying policy changes. Section IV describes our results. Finally, Section V concludes.

\section{The Empirical Model}

Here we briefly outline the econometric model used and we refer to the Online Appendix for a detailed description of the estimation procedure. As in Stock and Watson (2012), Mertens and Ravn $(2013,2014)$ and Stock and Watson (2018), we estimate a structural VAR that uses narratively identified tax changes as proxies. The starting point of our analysis is a reduced-form VAR written as

$$
X_{t}=c+\sum_{i=1}^{P} \beta_{i} X_{t-i}+\boldsymbol{\Gamma} \epsilon_{t}, \text { with } i=1,2, \ldots, P
$$

where $X_{t}$ is a vector of endogenous variables, $c$ is a constant term, $\beta_{i}$ are the $n \times n$ matrix of coefficients. The structural shocks $\epsilon_{t}$ are related to the VAR residuals $\mu_{t}$ via the relation $\boldsymbol{\Gamma} \epsilon_{t}=\mu_{t}$, where $\boldsymbol{\Gamma}$ is a $n \times n$ non-singular matrix of coefficients that satisfy $E\left(\mu_{t} \mu_{t}^{\prime}\right)=\boldsymbol{\Gamma} \boldsymbol{\Gamma}^{\prime}$.

Identification is reached by using the information from the narrative dataset to obtain co-variance restrictions for the structural shocks. First, we partition the vector of structural shocks as $\epsilon_{t}=\left[\epsilon_{\tau, t}^{\prime}, \epsilon_{z, t}^{\prime}\right]$, where $\epsilon_{\tau, t}$ is a $2 \times 1$ vector of the structural tax shocks of study, namely to AITR and ACTR, while $\epsilon_{z, t}$ of size $(n-2) \times 1$, represents all the other structural shocks to standard macroeconomic variables, see below. Second, let $q_{t}$ be a $2 \times 1$ vector of proxies. In order to use it for the identification of $\boldsymbol{\Gamma}, q_{t}$ needs to satisfy the following two conditions:

$$
E\left(q_{t} \epsilon_{\tau, t}^{\prime}\right)=\mathbf{\Psi} \neq 0
$$




$$
E\left(q_{t} \epsilon_{z, t}^{\prime}\right)=0
$$

Equation (2) states that the proxies $q_{t}$ are correlated with the structural tax shocks to be estimated, while (3) rules out any correlation between $q_{t}$ and the remaining structural shocks and establishes exogeneity of the proxies. These conditions, along with the requirement that the structural shocks $\epsilon_{t}$ are contemporaneously uncorrelated, can be used to derive an estimator for the two columns of $\boldsymbol{\Gamma}$ that correspond to $q_{t}$. Then, we can partition the matrix $\boldsymbol{\Gamma}$ as

$$
\boldsymbol{\Gamma}=\left[\begin{array}{ll}
\underbrace{\gamma_{\tau}}_{n \times 2} & \underbrace{\gamma_{z}}_{n \times(n-2)}
\end{array}\right] \text {. }
$$

From this, it can be shown that

$$
\Psi \gamma_{\tau}^{\prime}=\Sigma_{q \mu^{\prime}}
$$

Note that conditions (2) and (3) allow the proxies to contain measurement errors or to be asymmetric around zero. The proxies may also be correlated with each of the shocks in $\epsilon_{\tau, t}$, i.e. $\boldsymbol{\Psi}$ does not need to be diagonal. Finally, it is not required that the proxy variables are orthogonal to the history of $X_{t}$. However this latter condition can improve our identification strength, i.e. improve the reliability of the proxy. As such, we drop all the anticipated tax changes from the proxies.

\section{Construction of the Proxies and the Composition of Taxes}

Here we describe the construction of the proxies for income and consumption tax changes, i.e. $q_{t}$, used in our statistical model. We also present a brief discussion of the underlying policies that generated the major tax changes and how these policies impacted on the AITR, ACTR and their relative importance for aggregate fiscal revenues.

This paper uses Cloyne $(2012,2013 a)$ 's dataset of tax liabilities changes in order to create a narrative measure of legislated consumption and income tax liability changes in the United Kingdom at quarterly frequency, covering the sample 1973:III-2009:IV. ${ }^{2}$ We group the tax liabilities changes into the following subcomponents: i) Value-added tax liabilities (VAT), ii) consumption-related duties tax liabilities (Duties), iii) personal income tax liabilities (PI), iv) corporate tax liabilities (CI), v) national insurance tax liabilities (NIC), vi) petroleum income tax (PetIT) and vii) a residual category with other revenue changing tax measures

\footnotetext{
${ }^{2}$ The full narrative dataset containing all tax changes grouped by tax type and motivation can be found in Cloyne (2013b).
} 
(OT). ${ }^{3}$ We aggregate i) and ii) as consumption taxes, while we consider the total of iii), iv), v) and vi) as income taxes. Precise categorisation and grouping (as in Cloyne (2012)) are reported in the Online Appendix.

Cloyne (2012) provides a narrative accounting of tax changes from 1945. However, available data on consumption tax, in particular VAT revenues, necessary to calculate our measure of ACTR, are available only from 1973, when VAT was first introduced in the UK. Furthermore, as discussed above, the shorter sample under consideration is particularly suited to analyse the relative merits of the two tax components under consideration and the effects of compositional tax changes. ${ }^{4}$

We do not distinguish between personal and corporate taxation because precise data on the fiscal revenues for these two tax categories is not available prior to 1987. It is therefore not possible to calculate a reliable measure of average personal and corporate tax rate for the sample under consideration. Hussain and Liu (2018) get around this issue by considering the legislated tax changes in personal and corporate tax components directly as tax shocks, rather than, as here, as proxies for the latent shocks. However such an approach is prone to measurement error that has been shown to be important in practice in analysis of disaggregated tax components, see Mertens and Ravn (2013) and the Online Appendix. ${ }^{5,6}$

We then retain only those tax changes that are categorised by Cloyne (2012) as unambiguously 'exogenous', i.e. those changes uncorrelated with macroeconomic conditions and public spending. ${ }^{7}$ This is a fundamental step in order to comply with the identification conditions in (2) and (3). Furthermore, we focus on major, i.e. those liability changes that account for at least 5 percent of the budget in a given year, and 'non-anticipated' tax changes, i.e. those liability changes that were implemented during one quarter from their announcement date. The latter condition allows us to avoid possible anticipation effects of tax reforms, see Mertens and Ravn (2012). ${ }^{8}$ The Online Appendix describes the Cloyne (2012)'s classification method of the legislated tax changes.

We construct a quarterly dataset for each type of tax liability change by as-

\footnotetext{
${ }^{3}$ We group in the OT residual category: stamp duties, inheritance tax, landfill tax, business rate, aggregate levy, climate change levy and other minor taxes.

${ }^{4}$ Data on fiscal revenues can be found in ONS (2016d), ONS (2016c), HMRC (2016a), HMRC (2016b), HMRC (2016c). Further description of the data on fiscal revenues can be found in the Online Appendix.

${ }^{5}$ It is important to note that in terms of fiscal revenues, corporation taxes are small compared to personal income taxes. For example, in 2001 corporation tax revenues account for just a fifth of total income tax receipts.

${ }^{6}$ We consider NIC as part of income tax. As the Institute for Fiscal Studies (briefing note n. 9, 2009) explains: 'The link between the amount contributed and the benefit entitlement, which was once close, has now almost entirely gone and substantial progress has been made in aligning the NI rate structure and tax base with those of income tax. Most of this has occurred in the last 25 years'. This covers for most part of the sample considered here.

${ }^{7}$ For some tax changes, Cloyne (2012) provides a double classification, one exogenous and one endogenous. In order to make our exogeneity condition stronger, we exclude these policy changes.

${ }^{8}$ Using 'anticipated' tax changes as an external instrument in the 'Proxy-SVAR' framework invalidates the interpretation of the VAR reduced form residuals as prediction errors. In fact, due to the presence of foresight, the conditioning variables may not span the information set of forward looking agents.
} 
signing the change in the projected full-year revenue of the corresponding type to the specific quarter of the implementation date. Counting multiple actions in a given quarter, our dataset consists of about 150 major, exogenous, nonanticipated consumption and income tax changes over the sample. Then we convert the exogenous series of income and consumption tax liability changes into the corresponding average tax change as

$$
\Delta \tau_{t}^{i, n}=\frac{\left(N I C_{t}+P I_{t}+C I_{t}+P e t I T_{t}\right)}{\text { Aggregate Income at time } t}
$$

$$
\Delta \tau_{t}^{c, n}=\frac{\left(V A T_{t}+\text { Duties }_{t}\right)}{\text { Aggregate Consumption at time } t \text {-VAT and Duties receipts at time } t},
$$

where $\Delta \tau_{t}^{i, n}$ and $\Delta \tau_{t}^{c, n}$ represent the narrative average tax changes in income and consumption respectively as fraction of their corresponding contemporaneous tax bases. We use aggregate income, i.e. the sum of employment income (compensation of employees), self-employment income (mixed income) and profits (gross operating surplus) as the income tax base. ${ }^{9}$ Results are virtually identical if we scale the narrative tax changes by their tax bases at time $t-1$ or by nominal GDP. The variables $\Delta \tau_{t}^{i, n}$ and $\Delta \tau_{t}^{c, n}$ are our 'proxies' used to identify the latent structural AITR and ACTR shocks. In turn, AITR and ACTR are constructed as

$$
A I T R_{t}=\frac{\text { Total income tax receipts at time } t}{\text { Aggregate Income at time } t} ;
$$

$$
A C T R_{t}=\frac{\text { VAT receipts at time } t+\text { Duties receipts at time } t}{\text { Aggregate Consumption at Time } t \text {-VAT and Duties receipts at time } t} .
$$

In order to complement the description of dynamics of tax changes for the historical period under consideration, we also calculate a measure of aggregate average tax rate, (ATR) as the ratio of total tax revenues over GDP and the narrative series of aggregate tax changes $\left(\Delta \tau_{t}^{a, n}\right)$ as the aggregate of all exogenous, major and unanticipated narrative tax changes. ${ }^{10}$ These can be expressed as

$$
A T R_{t}=\frac{\text { Aggregate Tax Revenues at time } t}{\text { GDP at time } t}
$$

\footnotetext{
${ }^{9}$ Macroeconomic data are from ONS (2016d), ONS (2016b), ONS (2016a) FRED (2015) and BIS (2015). Further description of the data can be found in the Online Appendix.

${ }^{10}$ Other than income and consumption tax changes, we register several policy changes in Stamp-Duties, Inheritance Tax, Capital Gains Tax and Landfill Tax.
} 


$$
\Delta \tau_{t}^{a, n}=\frac{\text { Aggregate Tax Changes at time } t}{\text { GDP at time } t}
$$

The top row of Figure 1 presents the time series of AITR and ACTR as well as the narrative series $\Delta \tau_{t}^{i, n}$ and $\Delta \tau_{t}^{c, n}$. The bottom row of Figure 1 presents instead the ATR, the narrative series $\Delta \tau_{t}^{a, n}$ and, crucially, the relative shares of income and consumption tax revenues on the aggregate fiscal revenues. ${ }^{11} \mathrm{~A}$ few things are worth stressing. First, the AITR presents a cyclical pattern over the medium run, varying from almost 25 percent in 1974 to as low as 19 percent in 1993. Differently, the ACTR presents an upward trend during the Conservative Party tenures of Margaret Thatcher and John Major passing from as low as 9 percent in 1978 to above 20 percent after 1996. This upward trend was reversed by the Labour governments between 1997 and 2009. The relative importance of income and consumption taxes appears to be one of the main differences, when it comes to aggregate tax policies, between the Conservatives and the Labour governments. ${ }^{12}$

Second, ATR increased over the sample and it does not present any pronounced pattern for Prime Minister or party in power, passing from as low as 28 percent in 1973 to as high as 34 percent in 2001. Perhaps more interestingly, the relative importance of income and consumption tax revenues varied greatly over the period under consideration. In particular, and consistent with the dynamic behaviour of ACTR, the importance of consumption tax revenues more than doubled between 1979 and 1997, passing from as low as 15 percent of total revenues to around 35 percent. Specular to this, the relative importance of income tax revenues decreased substantially over the same period, passing from 70 percent of total revenues in 1978 to 55 percent in 1997.

This pattern had been mainly driven by the legislation passed by the Conservative party who shifted taxation from income to consumption in order to pursue long-run efficiency and growth, and it can be clearly seen in the narrative series $\Delta \tau_{t}^{i, n}$ and $\Delta \tau_{t}^{c, n}$ in the top row of Figure 1. Therefore, it is not surprising that two narrative series display a negative (and significant at 95 percent) correlation of -0.27 . Given this correlation, it would not be appropriate to consider the narrative income (consumption) tax changes as uncorrelated with exogenous shocks to the consumption (income) tax rate. Indeed, the strong link between income and consumption tax changes pushes for a joint identification scheme of shocks in AITR and ACTR. As we will show later on, this is a crucial aspect of our analysis.

\footnotetext{
${ }^{11}$ In order to make the narrative changes comparable across sub-plots, $\Delta \tau_{t}^{i, n}$ and $\Delta \tau_{t}^{c, n}$ are normalised as percentage of GDP.

${ }^{12}$ During the period under consideration the UK Prime Ministers were: Edward Heath, Conservative (-1974), Harold Wilson-Labour (1974-1976), James Callaghan-Labour (1976-1979), Margaret ThatcherConservative (1979-1990), John Major-Conservative (1990-1997), Tony Blair-Labour (1997-2007), Gordon Brown-Labour (2007-).
} 
Income Tax

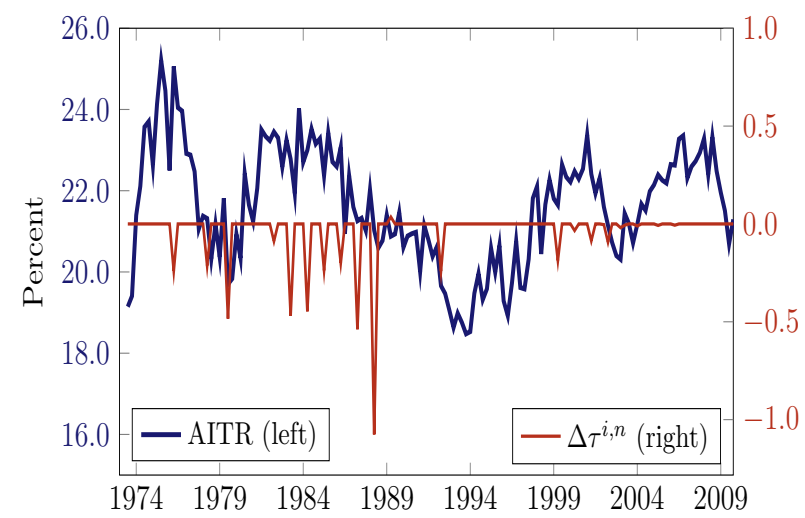

Aggregate Tax Rate

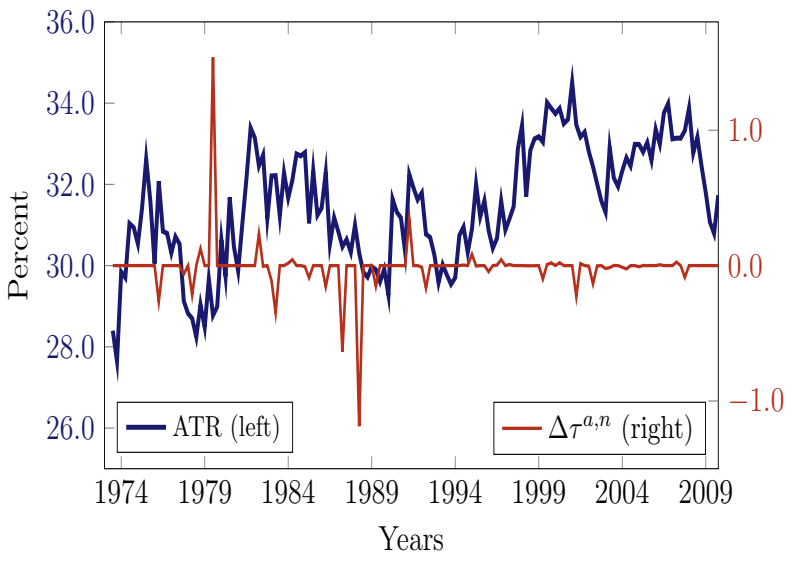

Consumption Tax

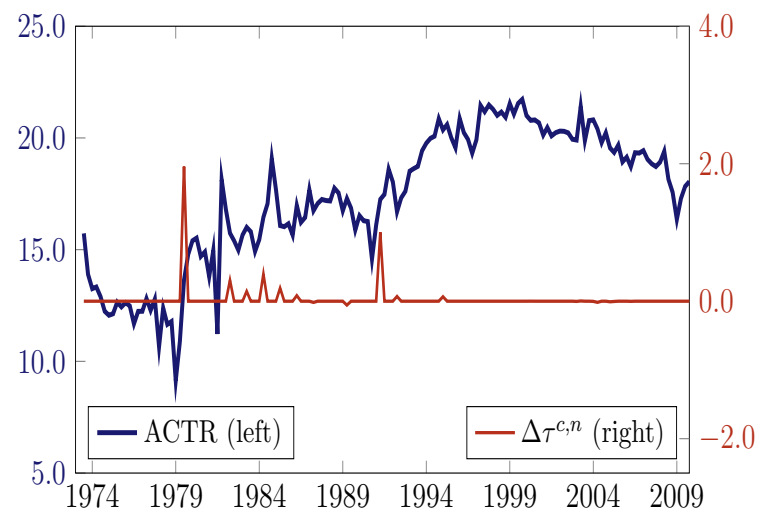

Figure 1. Average Tax Rates, Narrative Changes and Relative Shares of Tax Revenues.

The careful classification of the tax changes provided in Cloyne (2012), should guarantee that $\Delta \tau_{t}^{i, n}$ and $\Delta \tau_{t}^{c, n}$ comply with the exogeneity condition in (3). As discussed above, we also drop anticipated tax changes from the proxies in order to improve the identification strength. This is a common approach in the literature, see Mertens and Ravn $(2013,2014)$. Inthe Online Appendix we show that the policy changes implemented right after two general elections, in 1979:III and in 1988:II were predicted. We therefore eliminate these two episodes from our narrative account.

We then conduct Granger causality to check whether our resulting narrative measure of tax changes can be predicted from lagged macro variables such as 
GDP, consumption, investment and government spending. ${ }^{13}$ Table 1 shows that the hypothesis of no Granger causality cannot be rejected. ${ }^{14}$

Table 1 also presents a robustness check where we test whether or not the decision to act can be forecast from the past observations of macro variables using an ordered probit regression. As for the previous cases, the test indicates that we cannot reject the hypothesis of no predictability.

TABle 1 -CAusality test for $\Delta \tau_{t}^{c, n}$ AND $\Delta \tau_{t}^{i, n}$.

\begin{tabular}{l|c|c} 
Series & Test Statistic & $\boldsymbol{p}$-value \\
\hline$\Delta \tau_{t}^{c, n}$ & & \\
Granger causality & 10.04 & 0.86 \\
Ordered probit & 10.11 & 0.86 \\
\hline$\Delta \tau_{t}^{i, n}$ & & \\
Granger causality & 11.55 & 0.77 \\
Ordered probit & 13.72 & 0.62 \\
\hline
\end{tabular}

\section{Results}

This section presents the main results of the paper. First, we describe our benchmark econometric model and discuss a number of issues related to the validity of our estimation technique. Second, we present a set of estimated impulse response functions (IRFs) to average income and consumption tax changes. Third, we compare the response of the two tax components with a shock to the aggregate measure of taxation. Finally we propose a policy exercise in which we change the composition of taxes from income to consumption, keeping the total fiscal revenues fixed on impact.

The Benchmark Model. - Our benchmark econometric specification consists of a VAR with eight variables,

$$
X_{t}=\left[A C T R_{t}, A I T R_{t}, \ln \left(Y_{t}\right), \ln \left(C_{t}\right), \ln \left(I_{t}\right), \ln \left(G_{t}\right), R_{t}, \ln \left(P_{t}\right)\right],
$$

where $A C T R_{t}, A I T R_{t}$ are the average consumption and income tax rates, as presented above. Then, $\ln \left(Y_{t}\right), \ln \left(C_{t}\right), \ln \left(I_{t}\right), \ln \left(G_{t}\right)$ are the GDP, private consumption, investment and government spending (central government total expenditure

\footnotetext{
${ }^{13}$ We use four lags of the series, but results would be identical under different lag structures.

${ }^{14}$ We also test whether our constructed narrative series are Granger caused by movements in fiscal variables (government spending, ACTR, and AITR), labour variables (wages and unemployment rate), inflation and monetary variables (interest rate and monetary base). None of these tests rejects the hypothesis of Granger non-causality of these variables to our narrative tax measures.
} 
on consumption and investment), respectively. These variables are expressed in $\operatorname{logs}$, real, per-capita. Finally, $R_{t}$ represents the three-month treasury bill rate and $\ln \left(P_{t}\right)$ is the (log of) prices, i.e. the deflator of household consumption expenditures, the closest measure to the Consumer Price Index (not available for the entire sample). ${ }^{15}$ All variables are at quarterly frequency and our sample is 1973:III-2009:IV. Based on the AIC and the LR Test, the lag length in the VAR is set to three. However, we have also experimented with different lags and results do not change, see the Online Appendix.

Identification Issues. - Given the observed correlation between the two tax categories, when measuring the effects of changing one tax, one needs to control for contemporaneous changes in the other tax. Section IV.A shows that ignoring this correlation would radically change the IRFs analysis.

Ideally, we would like to identify the effects of income and consumption taxes separately. Unfortunately, the number of policy changes when only one tax component was altered in isolation to the other are extremely rare to have a sound econometric identification. ${ }^{16}$ Therefore, we need a joint identification scheme for the shocks in the two tax components as we cannot impose that the proxy for one tax shock is orthogonal to the other tax shock. In the benchmark model, we accomplish this task by adopting a Cholesky decomposition, as it is standard in the literature, see Mertens and Ravn (2013) and Caldara and Kamps (2017). To illustrate this point, we express the relationship between the VAR residuals of $\mu_{t}$ and the structural shocks $\epsilon_{t}$ as

$$
\begin{aligned}
& \mu_{\tau, t}=\varrho \mu_{z, t}+\mathbf{B}_{\tau} \epsilon_{\tau, t} \\
& \mu_{z, t}=\vartheta \mu_{\tau, t}+\mathbf{B}_{z} \epsilon_{z, t}
\end{aligned}
$$

where $\mu_{\tau, t}$ and $\epsilon_{\tau, t}$ are the reduced-form innovations and the structural tax rate shocks, respectively, while $\mu_{z, t}$ and $\epsilon_{z, t}$ represent the reduced form innovations and the structural shocks of all other $z$ variables in our benchmark specification (12). The matrices $\varrho, \vartheta, \mathbf{B}_{\tau}$, and $\mathbf{B}_{z}$ hold the structural coefficients of $\boldsymbol{\Gamma}$ introduced in (1). In order to study the response to $\epsilon_{\tau, t}$, we require the identification of the first two columns of $\boldsymbol{\Gamma}$, i.e. $\gamma_{\tau}$. By using (5), (13) and (14), we can derive $\gamma_{\tau}$ as

$$
\gamma_{\tau}=\left[\begin{array}{c}
\mathbf{I}+\varrho(\mathbf{I}-\vartheta \varrho)^{-1} \vartheta \\
(\mathbf{I}-\vartheta \varrho)^{-1} \vartheta
\end{array}\right] \mathbf{B}_{\tau}
$$

\footnotetext{
${ }^{15}$ See the Online Appendix for results with different definitions of the price index.

${ }^{16}$ Despite this, in the Online Appendix we consider an alternative set of proxies where we retain only those episodes when consumption tax changes did not occur at the same time as income tax changes and episodes which were mostly consumption tax led or mostly income tax led and results do not change.
} 
Using (15), we identify the term in square bracket, i.e. $\gamma_{\tau} \mathbf{B}_{\tau}^{-1}$, and the covariance matrix $\mathbf{B}_{\tau} \mathbf{B}_{\tau}^{\prime}$. In particular, we estimate $\vartheta$ by using $q_{t}$ as instruments for $\mu_{\tau, t}$. Once we have estimated $\vartheta$, we use $\left(\mu_{z, t}-\vartheta \mu_{\tau, t}\right)$ as instruments to estimate $\varrho$. Then, the covariance of $\left(\mu_{\tau, t}-\varrho \mu_{z, t}\right)$ can be used to estimate $\mathbf{B}_{\tau} \mathbf{B}_{\tau}^{\prime}$. However, these covariance restrictions do not suffice to estimate all the elements in $\mathbf{B}_{\tau}$, which is required if one is interested in studying the impact of a change in a specific tax component, i.e. consumption tax shock or income tax shock. ${ }^{17}$ To deal with this issue, we employ a Cholesky decomposition of $\mathbf{B}_{\tau} \mathbf{B}_{\tau}^{\prime}$ which results in a lower (or upper) triangular $\mathbf{B}_{\tau}$.

Accordingly, the ordering of tax rates in the model matters. In order to make the interpretation of the different orderings as transparent as possible, we follow the analysis in Mertens and Ravn (2018). For this purpose, let us rewrite (13) as

$$
\left[\begin{array}{c}
\mu_{t}^{A I T R} \\
\mu_{t}^{A C T R}
\end{array}\right]=\varrho \mu_{z, t}+\mathbf{B}_{\tau}\left[\begin{array}{c}
\epsilon_{t}^{A I T R} \\
\epsilon_{t}^{A C T R}
\end{array}\right]
$$

with the superscripts AITR and ACTR identify variables related to two tax components of interest. The upper triangular restriction on $\mathbf{B}_{\tau}$, i.e. $B_{2,1}=0$, produces the response to an unanticipated income tax change that affects the AITR but has no impact on the ACTR in cyclically adjusted terms, i.e. after accounting for contemporaneous feedback from $\mu_{z, t}$, as any direct effect of the AITR shock on the ACTR in (16) is imposed to be zero on impact. As such, this identification strategy is also known as 'exclusion restriction' or 'zero restriction'. The same restriction $\left(B_{2,1}=0\right)$ also identifies the response to an unexpected change in the ACTR, but permitting for a simultaneous exogenous change in the AITR. The same logic applies, ceteris paribus, for the alternative lower triangular restriction in which $B_{1,2}=0 .{ }^{18}$ As such, different restrictions on the matrix $\mathbf{B}_{\tau}$ change the economic nature of the implied impulse responses. In this sense, only the upper triangular restriction $\left(B_{2,1}=0\right)$ isolates the effects of an unexpected change in AITR, while only the lower triangular restriction $\left(B_{1,2}=0\right)$ isolates the effects of an unexpected change in ACTR. While all our IRFs to a tax rate shock show the estimates resulting from these restrictions, results are virtually identical under the alternative ordering $\left(B_{1,2}=0\right.$ for AITR shock and $B_{2,1}=0$ for ACTR shock), see the Online Appendix.

The identification strategy used here amounts to imposing an exclusion restrictions between the two tax shocks. In Section IV.A we propose, as alternative to Cholesky, a sign restriction identification scheme that does not require triangulation of the matrix $\mathbf{B}_{\tau}$, and assume instead that the tax shock in one tax component correlates more, on impact, with variations in the corresponding tax

\footnotetext{
${ }^{17}$ Without identification of $\mathbf{B}_{\tau}$, our usage of proxies only permits the structural analysis to linear combinations of two tax shocks.

${ }^{18}$ In this case the response to an unanticipated consumption tax change affects the ACTR but has no impact on the AITR, while the response to an unexpected change in the AITR allows for a simultaneous exogenous change in the ACTR.
} 
rate. For example, a shock of income tax correlates more on impact with AITR than with ACTR.

Our 'Proxy-SVAR' specification treats the narrative dataset as imperfect measures of the latent structural tax shocks. Thus, it produces estimates that are robust to potential measurement errors, as long as conditions (2) and (3) are satisfied. We discussed condition (3) in Section (III). In order to evaluate condition (2), i.e. how much information our narrative dataset contains about the latent structural shocks, we adopt a reliability measure as in Mertens and Ravn (2013). This evaluation consists in calculating the eigenvalues of the statistic $\Xi$ as,

$$
\Xi=\frac{1}{d} \Sigma_{q q^{\prime}}^{-1} \Sigma_{q \mu_{\tau}^{\prime}}\left(\gamma_{\tau \tau} \gamma_{\tau \tau}^{\prime-1}\right) \Sigma_{q \mu_{\tau}^{\prime}}^{\prime}
$$

where $d$ is the fraction of uncensored observations of $q_{t}$ and $\gamma_{\tau \tau}$ identifies the 2by-2 top elements of the matrix $\gamma_{\tau}$. The eigenvalues of $\Xi$ can be seen as measure of reliabilities of the principal components of the uncensored observations in $q_{t}$. In our benchmark specification, the eigenvalues of the estimated $\Xi$ matrix are 0.19 and 0.62 , with 90 percent bounds $[0.07,0.27]$ and $[0.55,1.00]$. Therefore, the correlations between the principal components of the narrative tax changes and the latent tax shocks are 0.44 and 0.79 .

The reliability matrix reveals that the proxies contain useful information for the identification of the structural tax shocks and that there is a fairly strong relation between the SVAR shocks and narrative changes to the tax components. However, the fact that the eigenvalues of $\Xi$ are substantially smaller than 1 , indicates that measurement error is a serious matter in practice. We also calculate the $R^{2}$ statistics for regressions of the reduced form residuals of ACTR and AITR on non zero observations of the proxies $q_{t}$. We find values of 0.23 and 0.17 , which show that the narrative changes explain a considerable fraction of the prediction error variance of the average income and consumption tax rates.

The Impulse Response Functions (IRFs). - Now we turn our attention to the analysis of the IRFs. We report the response of the observables in (12) to a 1 percentage point cut in each tax rate, respectively. ${ }^{19}$ We also calculate the confidence intervals with the parametric bootstrap as in Montiel-Olea, Stock and Watson (2017), extended to the case with 2 proxies and 2 shocks, and a Newey and West (1987) HAC-robust residual covariance matrix as in Mertens and Montiel-Olea (2018). The parametric bootstrap is based on draws from a joint normal distribution for all the model parameters using the estimated values and covariance matrix. Consistent with Brüggemann, Jentsch and Trenkler (2016) and Jentsch and Lunsford (2018), the approach adopted here yields intervals that are asymptotically valid.

\footnotetext{
${ }^{19}$ We present the median in order to make the results from the Cholesky identification scheme comparable with the ones obtained with sign restriction, where it is standard practice to use the median value.
} 
Alongside the IRFs we also calculate the present value multiplier at a generic lag $k\left(P V M_{k}\right)$, where we normalise the cumulative discounted response of GDP by the movement of each the tax rate along the response path, i.e.

$$
P V M_{k}=\frac{\sum_{i=0}^{k}(1+\bar{r})^{-i} y_{i}}{\sum_{i=0}^{k}(1+\bar{r})^{-i} f_{i}},
$$

where $y_{i}$ is the response of GDP at period $i, f_{i}$ is the response of the tax rate at period $i, \bar{r}$ is the average quarterly real interest rate over the sample. Finally, to ease comparison between different tax components, we also present the present value multiplier rescaled by the ratio of GDP to the relevant tax base, i.e. $P V M_{G D P, k}$. In this case tax shocks in each tax component should be interpreted as 1 percent cut in GDP terms. In this way we can control for the different tax bases of income and consumption taxation. We start by exploring the effects of an unexpected AITR cut, see Figure 2.

The key finding from this exercise is that cuts in AITR generate large and persistent short-run expansions on total output and its (private) expenditure components. GDP increases on impact by around 0.78 percent $(p=0.14)$, it peaks at $1.50(p=0.048)$ in the fourth quarter after the tax shock and then gradually fades away. Regarding the private expenditure components, households final consumption increases by 1.20 percent on impact $(p=0.05)$ and it reaches its peak at 1.60 percent $(p=0.04)$ after 4 quarters. This suggests that income tax shocks have very similar effects on private consumption and on GDP. Private investment displays the largest response to income tax shocks: a 1 percentage point cut in AITR generates a contemporaneous increase in investment of 2.70 percent $(p=0.07)$, with a maximum effect of 4.60 percent $(p=0.03)$ one year after the shock. All these variables display a hump-shaped pattern, as typically found by the empirical macroeconomic literature. The PVM of a cut in AITR is around 2 percent after one year $(p=0.05)$ and reaches its peak after two years at 2.36 percent $(p=0.065)$, while in GDP tax base terms, the peak effect is 2.62 , see Table 2.

Despite the boost in the overall economic activity, tax revenues from income taxation decrease on impact by around 4 percent, and they remain significantly below their average for six months. ${ }^{20}$ This result is expected, as the UK appears

\footnotetext{
${ }^{20}$ In order to calculate the response of fiscal revenues to a tax change, we combine the estimated responses of the specific tax base and tax rate. The formulas for the response of income tax revenue and consumption tax revenue read as, respectively

$$
\begin{gathered}
\widehat{t r}_{t}^{A I T R}=\frac{\widehat{A I T} R_{t}}{\overline{A I T R}}+\widehat{y}_{t}, \\
\widehat{t r}_{t}^{A C T R}=\frac{A \widehat{C T} R_{t}}{\overline{A C T R}\left(1+\widehat{A C T R}+\widehat{A C T} R_{t}\right)}+\widehat{c}_{t},
\end{gathered}
$$
}

where $\widehat{x}_{t}$ represents the impulse response of $x_{t}$, lower case letters represent logged variables, and overlined variables denote the mean average of the corresponding variable. 

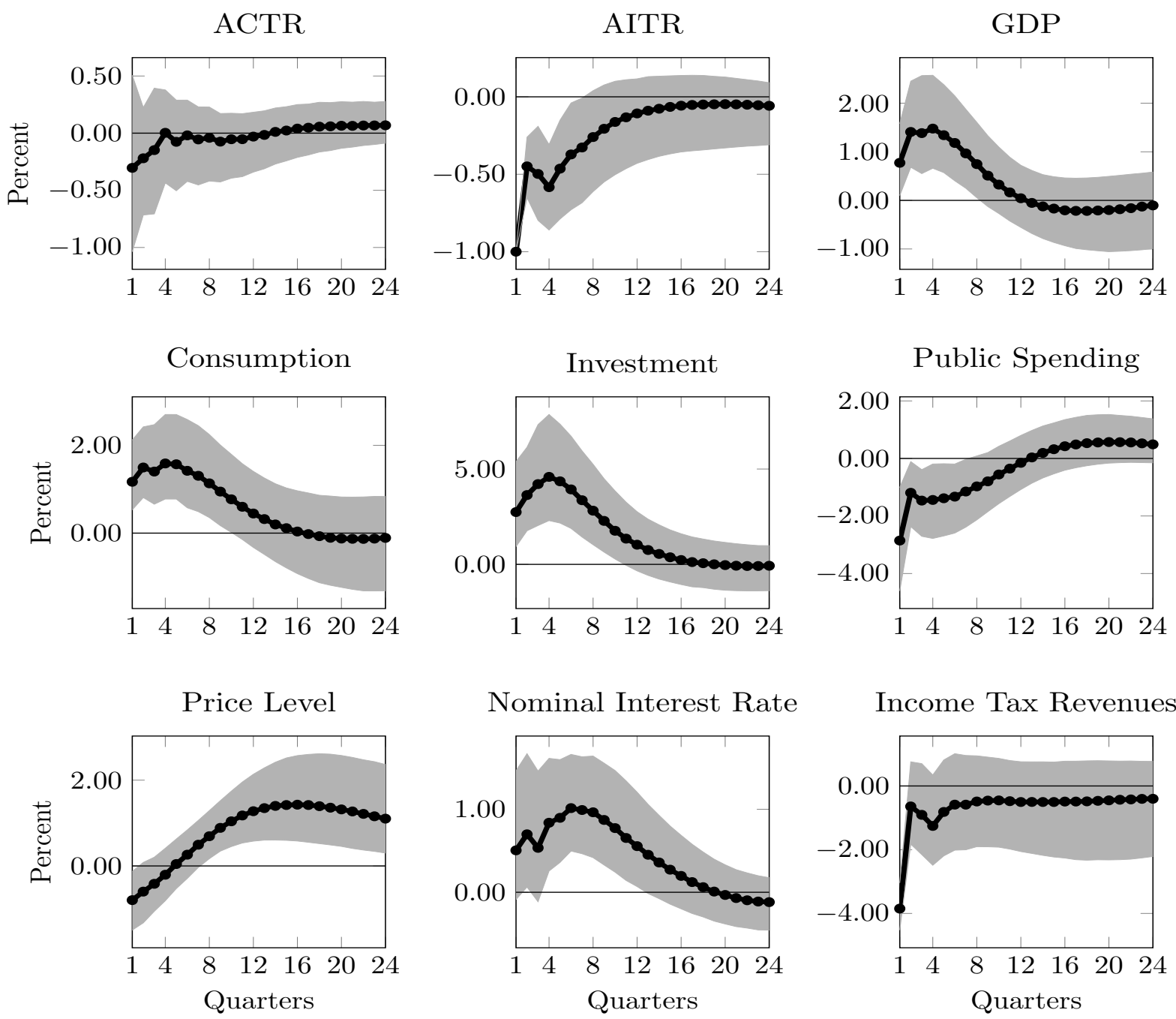

Income Tax Revenues

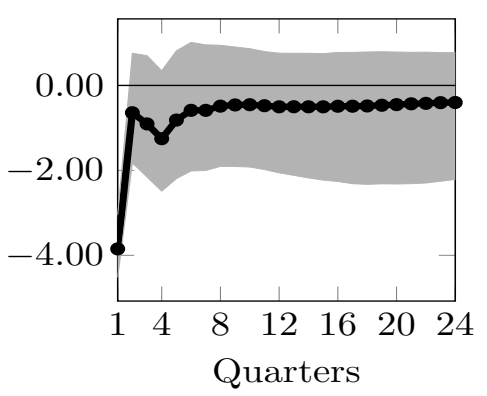

Figure 2. IRFs to a one percentage point cut in AITR. Shaded areas represent the 68 Percent CONFIDENCE BOUNDS.

to be on the increasing side of the Laffer Curve for income tax components (a cut in average tax rates implies a decrease in revenues), see Trabandt and Uhlig (2011, 2012).

Perhaps more interestingly, our results suggest that public spending decreases on impact by roughly 3 percent $(p=0.10)$ and remains below its average for several quarters, thus reflecting some sort of fiscal discipline: as the tax revenues decrease so does government consumption. ${ }^{21,22}$ This result is particularly inter-

${ }^{21}$ This implies a reduction of the government spending-to-GDP ratio of around 0.9 percent.
${ }^{22}$ As in Mertens and Ravn (2013), Government Spending is defined as the Central Government Con- 
esting, as the fiscal policy literature generally finds that aggregate tax cuts do not 'Starve the Beast', i.e. government spending does not respond to tax changes, e.g. Romer and Romer (2009). It is important to stress that our narrative account of tax shocks does not include spending-driven, deficit reduction or countercyclical motivated tax changes. These episodes are classified as endogenous and their inclusion would likely bias our results either towards or against a 'Starve the Beast' effect. Differently, here the negative response of government spending to income tax cuts is driven by exogenous policy changes that are not made in response to current macroeconomic conditions or in conjunction with spending changes. Despite this, there might still be a bias that works in the direction of a 'Starve the Beast' effect: a desire for a smaller government. However the motivations of our exogenous tax changes rarely refer to future adjustments in government spending. Therefore, this source of bias is likely to be limited.

Our benchmark econometric specification also includes a measure of the price level and of monetary policy. This is important for at least two reasons. First, the sign of the price level response is indicative of whether the expansionary effects of income tax cuts are primarily derived from an increase in aggregate demand or in supply of final goods. Secondly, the response of monetary policy is generally quite important in shaping the equilibrium effects of fiscal policy, see Leeper (1991) and Woodford (1995), among others. We find that prices fall on impact, -0.80 percent $(p=0.12)$, underlying a possible supply-side effect of tax shocks. Our estimates also indicate that prices increase over time, peaking at 1.40 percent $(p=0.06)$ 4 years after the shock and thus suggesting a demand-side effect over both the medium and long-run. The nominal interest rate is significantly above zero for 13 quarters after the tax change, with a maximum response at 1.02 percent $(p=0.04)$ in the sixth quarter, revealing some monetary policy concerns about the increase in the price level. Remarkably, our findings on prices and interest rate are similar to the effects of an aggregate tax shock presented in Cloyne (2013a).

Movements in AITR have also expansionary effects on labour market variables. $^{23}$ At its peak, a one percentage point cut in AITR decreases the unemployment rate by 0.52 percentage points $(p=0.045), 6$ quarters after the shock and, in the same quarter, increases hours by around 0.23 percent $(p=0.13)$. We also register a positive response of real wages with a marginal significance at 68 percent.

In the Online Appendix we also investigate the effects of AITR shocks on the international dimension of fiscal policy, such as on the nominal exchange rate, the term of trade, import and export. The main finding from this exercise is that the open-economy spillovers coming from income tax shocks are weak and not statistically significant.

Now we turn our attention to consumption tax shocks. Figure 3 reports the IRFs to a one percentage point cut in ACTR. Fiscal revenues for this tax com-

sumption plus Gross Investment, divided by GDP deflator.

${ }^{23}$ For the sake of brevity we report the IRFs of this exercise in the Online Appendix. 
ponent decrease significantly by around 4.5 percentage points $(p=0.013)$. This result is consistent with the notion that the Laffer curve for consumption taxation peaks at infinity, i.e. the marginal increase in consumption tax revenues implied by a tax hike is always greater than its marginal distortionary effect on its tax base, see Trabandt and Uhlig (2011). We also register a significant pass-through of the consumption tax shock to the price level, with a decrease by 0.65 percent in the second quarter $(p=0.1)$. This result is mainly due to the accounting measure of the price level, which includes consumption taxes. The nominal interest rate does not respond significantly, suggesting that monetary policy reacts weakly to price changes caused by direct variations of consumption taxes.

The main result of Figure 3 is that, in contrast to the large and persistent expansionary effects found under income tax changes, shocks to consumption taxes have a modest and not statistically significant effect on output and its components. The response of GDP is insignificant at all forecast horizons and peaks around 0.2 percent seventh quarters after the shock. We obtain similar quantitative results for private consumption, however we find a marginally significant expansionary effect on durable consumption, see the Online Appendix. The response of private investment is negative for part of the horizon, with a maximal reduction of 0.7 percent. However this response is not statistically different from zero at 68 percent. We find a positive response of government spending, but again, this effect is not significant at standard levels. The PVM of ACTR cuts is rather small, i.e. below 0.3 percent (or 0.58 in GDP tax base terms), and it is not statistically different than zero for standard significance levels. We also register a small decrease in AITR one year after the consumption tax shock. However, this effect does not appear to be a robust result and it disappears, for instance, in models that include the exchange rate.

Along this line, ACTR shocks have no relevant effects on labour market variables: the responses of unemployment and hours are not statistically different to zero, while real wages increase on impact, mainly for accounting reasons as price falls, see the Online Appendix. As for the AITR shocks, we do not find any spillovers from ACTR shocks to open economy variables. The responses of the nominal exchange rate, the term of trade, import and export are not statistically significant at 68 percent level.

In the Online Appendix, we also check the robustness of our results by considering an alternative set of proxies. In particular we consider those episodes where consumption tax changes did not occur at the same time as income tax changes and episodes which were mostly consumption tax led or mostly income tax led. In each of these cases, we treat as 'endogenous' the changes in the other tax component. In this way we artificially eliminate any correlation between the proxies. Results remain, for all practical purposes, reassuringly similar to the benchmark. ${ }^{24}$

\footnotetext{
${ }^{24}$ We also run a robustness check by applying Winsorizing to our narrative series, and results do not change. Likewise, our results hold if we eliminate all the narrative changes smaller than a certain
} 


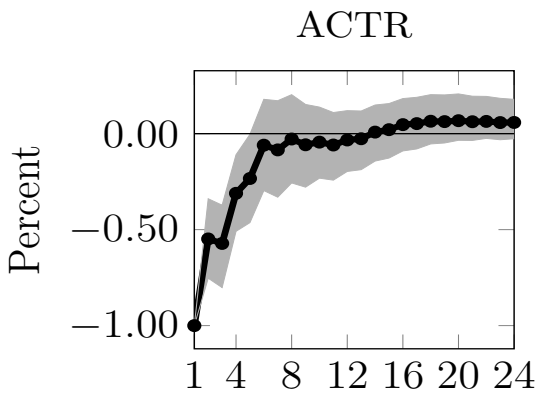

Consumption

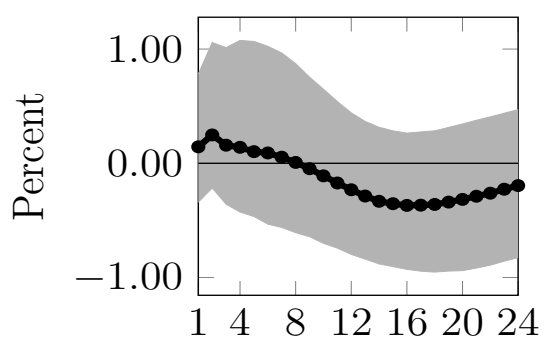

Price Level

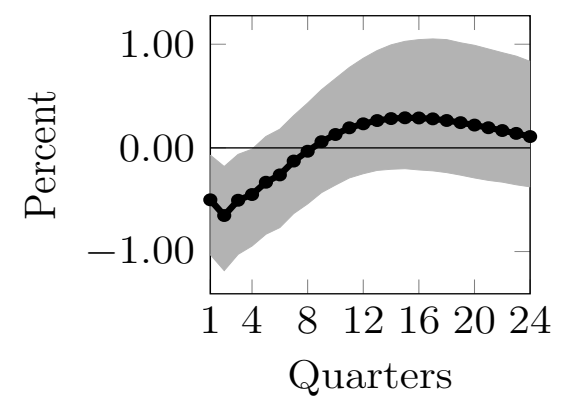

AITR

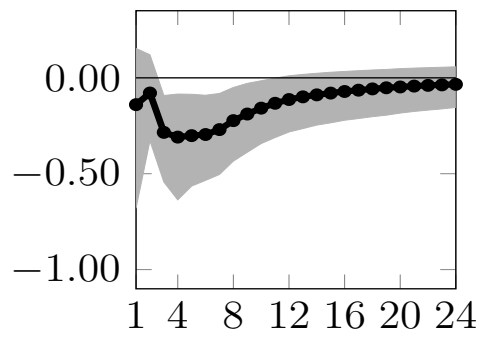

Investment

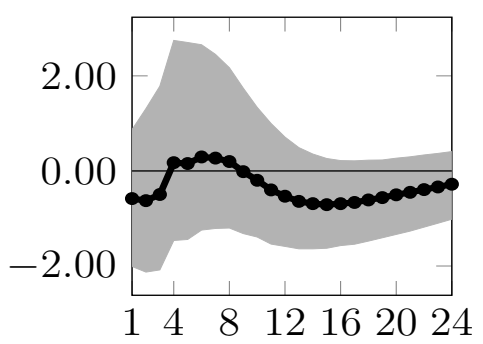

Nominal Interest Rate

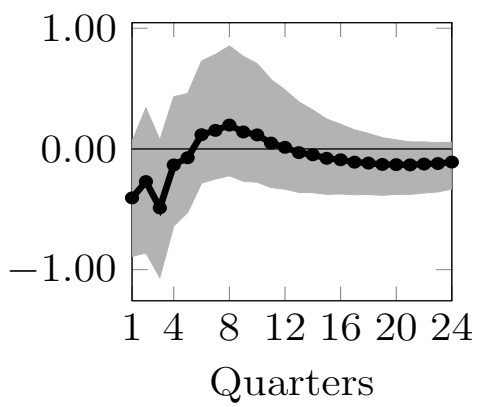

GDP

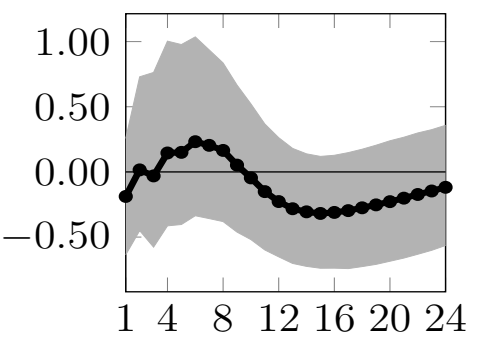

Public Spending

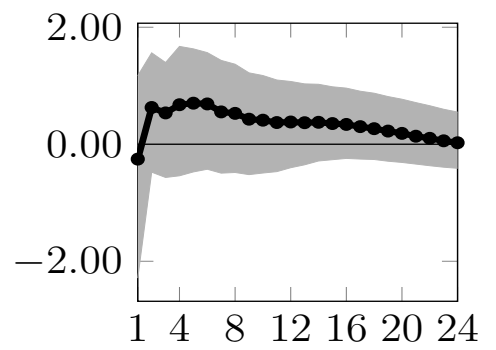

Consumption Tax Revenues

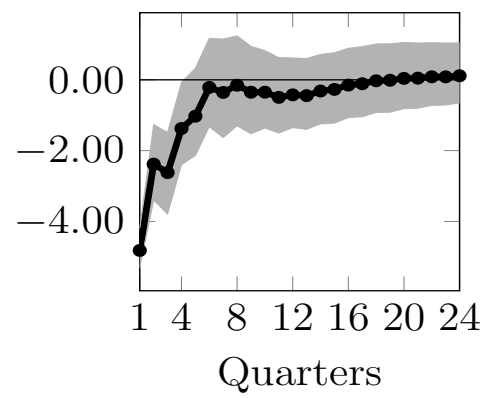

Figure 3. IRFs to a one Percentage point CUt in ACTR. Shaded AReas Represent the 68 PerCent CONFIDENCE BOUNDS.

We believe these results are important for two reasons. First, they offer robustness that our effects are not primarily driven by the correlation of the proxies. Second, they stress the importance of a joint identification scheme for the shocks in the two tax components. In other words, the proxies in each tax component are useful for the identification of the shocks in both tax components.

In the Online Appendix, we present a General Equilibrium model that can replicate qualitatively the different multipliers of income and consumption tax

threshold (1 standard deviation), i.e. we keep only very large tax changes. In addition, using the pre-2008 sample, i.e. to exclude the effects caused by the recent global financial crisis, leads to similar results. 
shocks found in our empirical analysis. The aim of our model is to generate intuitions behind our empirical results but it is not meant to provide any definitive quantitative answer.

The main intuition that emerges from the model is the following. First, a cut in ACTR triggers a relative price change, as consumption becomes cheaper than investment. The resulting substitution effect induces a decrease in saving and investment. Lower investment dampens the ACTR multiplier on current GDP and on future consumption. Differently, cuts in AITR do not trigger any significant relative price change between investment and consumption. This results in an increase in all private expenditure components and a big multiplier effect on GDP.

Second, for a given level fiscal revenues, the consumption tax combines a onetime, non-distortionary lump-sum on part of the (inelastically supplied) initial level of wealth, with an income tax. Since income tax itself is distortionary, it is natural to expect that the wealth effect of a cut in ACTR to be smaller than the one implied by a cut in AITR.

Table 2-Present value multipliers of Different tax shocks.

\begin{tabular}{l|ccccc|c|c} 
& $\mathbf{1}$ qrt & $\mathbf{4}$ qrts & $\mathbf{6}$ qrts & $\mathbf{8}$ qrts & $\mathbf{1 2}$ qrts & PVM $^{\max }$ & PVM $_{\mathrm{GDP}}^{\max }$ \\
\hline AITR Shock & $0.78^{*}$ & $1.98^{* *}$ & $2.24^{*}$ & $2.35^{*}$ & $2.26^{*}$ & $2.36^{*}($ qrt 9) & $2.62^{*}$ (qrt 9) \\
ACTR Shock & -0.19 & -0.01 & 0.14 & 0.27 & 0.18 & 0.29 (qrt 10) & 0.58 (qrt 10) \\
\hline
\end{tabular}

Note: Present value multipliers for one percentage point cut in AITR and ACTR. PVM ${ }^{\text {max }}$ shows the maximal present value multipliers for one percentage point cut in either AITR or ACTR. PVM $\mathbf{G D P}_{\mathrm{GDP}}^{\max }$ shows the maximal present value multipliers for cut in either AITR or ACTR, normalised by GDP. Asterisks ${ }^{*}$ and ${ }^{* *}$ mean 68 and 90 percent significance, respectively.

Aggregate Tax Shock. - Alongside the transmission mechanism of income and consumption tax changes, it is instructive to analyse the effects of an exogenous cut in the general level of taxation, i.e. the average tax rate, ATR. In this way we can shed light on the importance of studying different tax components separately. In this case the econometric model substitutes the ATR for ACTR and AITR, and includes all the other macroeconomic observables in (12). ${ }^{25}$

The findings from a shock to the general level of taxation (ATR) are presented in Figure 4. There are two results worth stressing. First, the expansionary effects of a one percent cut in ATR are quantitatively similar to the ones obtained under AITR. This is true for GDP and its private components, as well as for the response of prices and interest rate. In this sense, the general message is that the large

\footnotetext{
${ }^{25}$ Note that we can not identify in the same model a shock to the general level of taxation and shocks to its components, given the standard orthogonality assumption of structural shocks. In the Online Appendix we analyse the alternative case where the aggregate tax shock is interpreted as two negative shocks in income and consumption tax rates.
} 
ATR multipliers found in the literature, e.g. Romer and Romer (2010) and Cloyne (2013a), are mainly influenced by changes in AITR. ${ }^{26}$

Second, the response of government spending to an ATR shock is no longer significant at 68 percent. This is important as it allows to reconcile our results with the general consensus in literature that finds no significant response of public good provision in response to movements in ATR, e.g. Romer and Romer (2010) and Cloyne (2013a). This suggests that the 'Starve the Beast' effect is specific to exogenous changes in AITR.

Revenue Neutral Experiment. - Having explored the quantitative outcomes of AITR and ACTR tax cuts, as well as the ones from a reduction in the general level of taxes, we now turn our attention to the effects of changing the composition of fiscal revenues. This exercise complements the previous ones on tax cuts. In those cases we analysed the effects of reducing the size of revenues, both through lowering different tax components and through cutting the aggregate tax rate. Here we study instead the consequences of shifting the burden of taxation from income to consumption, keeping the size of fiscal revenues fixed (on impact). This exercise is important for two reasons. First, it allows us to shed light from an empirical point of view on the conventional public finance theories: shifting the burden of taxation from income to consumption increases efficiency and is therefore expansionary, see inter alia Coleman (2000), Altig et al. (2001) and Correia (2010). ${ }^{27}$ Second, it is important in practice, as it evaluates from an empirical point of view the effects of the fiscal policy reforms implemented in the UK during the period under consideration, where cuts in personal and corporate income taxes were often balanced with increases in VAT and other consumption duties such as on fuel, alcohol and tobacco.

The analysis is conducted under our benchmark identification technique with the set of observables in (12). We study the linear combination of two shocks (positive to ACTR and negative to AITR) such that the resulting effects on revenues is zero on impact. Formally, we choose the size of the shocks $\epsilon_{t}^{A I T R}$ and $\epsilon_{t}^{A C T R}$ such that on impact, the decrease in revenues from a cut in AITR is compensated by the increase in revenues from a hike in ACTR.

Figure 5 presents the results of this policy experiment. A few things are worth stressing. First, changing the composition of fiscal revenues from income to consumption leads to an expansionary effect on GDP, which is significant at 68 percent and lasts for six quarters. In this sense the expansionary effects of a cut in AITR are so strong in magnitude that drive output outward despite the increase

\footnotetext{
${ }^{26}$ In particular the peak effect on GDP is $1.4(p=0.09)$, on private consumption is $1.51(p=0.09)$ and on investment is $2.95(p=0.1)$.

${ }^{27}$ From a theoretical perspective, the type of revenue neutral policies analysed here, i.e. shifting the composition of taxes from income to consumption, have been shown to be effective in open economy contexts with fixed exchange rate regime such as in a Monetary Unions, see inter alia Farhi, Gopinath and Itskhoki (2014). In these cases, educated revenue neutral policies that implement VAT increases and uniform payroll tax reductions, can replicate the flexible exchange rate allocations.
} 

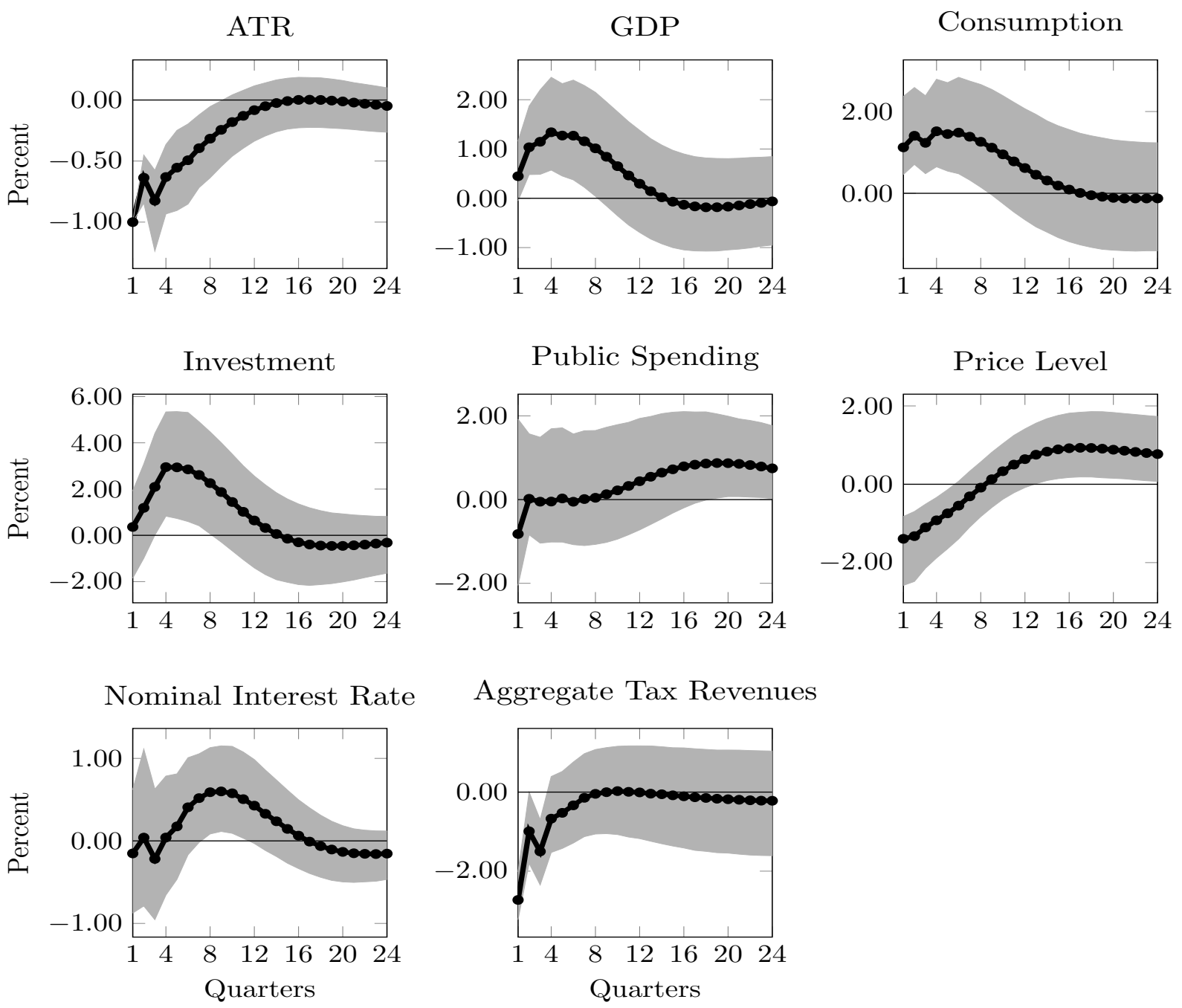

Figure 4. IRFs to a one Percentage point CUt in ATR. Shaded AREAS Represent The 68 Percent CONFIDENCE BOUNDS.

in ACTR. This result is in line with standard public finance theories. We conduct the same revenue neutral policy experiment in our theoretical model, obtaining results that are qualitatively comparable to the ones obtained here, see the Online Appendix.

Second, while fiscal revenues are zero on impact, they increase in the third quarter after the shock. This is due to the fact that revenues are positively correlated with GDP. As the latter increases so does the former. Third, the impact response of ACTR is larger than the one of AITR as consumption tax base is smaller than total income tax base. Fourth, our revenue neutral policy experiment produces 
larger confidence bounds than the benchmark exercises. This is a consequence of hitting the system with two shocks which inevitably increases the uncertainty of the estimates.
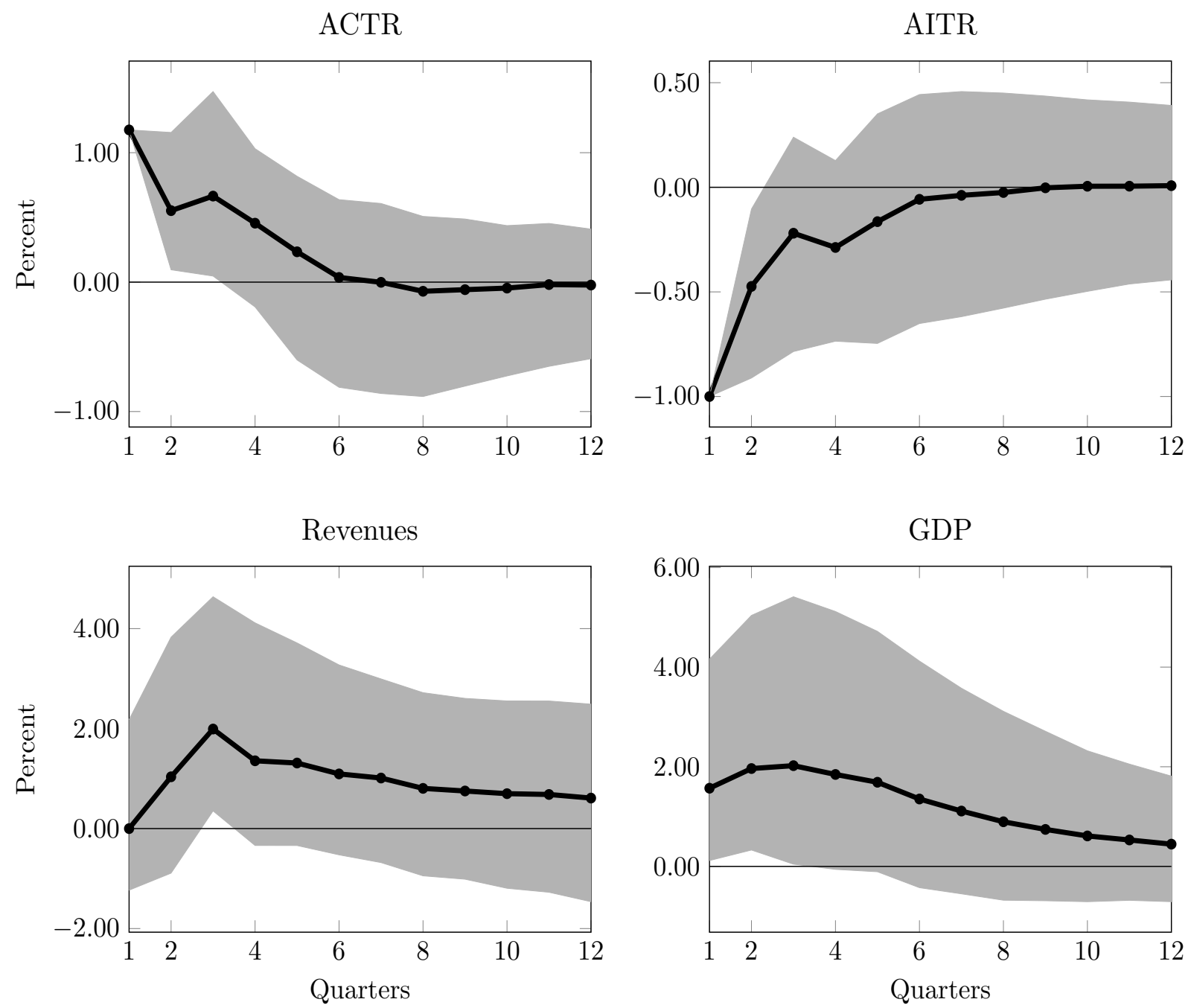

Figure 5. Revenue Neutral Exercise. Shaded areas represent the 68 Percent Confidence BOUNDS.

\section{A. Alternative Identification Schemes}

This section discusses in further details crucial aspects of the joint identification issue of income and consumption tax shocks. To this end, we start by highlighting 
the importance of allowing for a joint identification scheme for our structural tax shocks and show how we can reconcile our results on ACTR shocks with the existing literature. Next, we propose a different identification procedure based on the literature of narratively identified sign restriction VARs. The reader can find in the Online Appendix other important identification issues, such as controlling for measurement and timing errors in our constructed series.

The Single Tax Proxy. - As described earlier in the paper, our narratively identified changes in income and consumption taxes correlate with each other. Therefore, it is probable that changes in one tax component correlate with shocks in both taxes. As explained above, we control for contemporaneous variation in both taxes by relying on standard Cholesky decomposition to deal with the insufficient number of identifying restrictions.

Here we follow Mertens and Ravn (2013) and discuss the importance of a joint identification scheme, where proxies in each tax component serve to identify shocks in both tax components. We do so by making the alternative assumption that each of the proxy correlates with only one tax shock, e.g. the proxy on consumption tax changes correlates only with ACTR. This means that each tax shock can be identified by using a single proxy.

In particular, we run two models, one for each tax shock component, with the same observables as in the benchmark (12). For example, for the case of AITR shock, we express the relationship between the VAR residuals $\mu_{t}$ and the structural shocks $\epsilon_{t}$ as

$$
\begin{gathered}
\mu_{A I T R, t}=\varrho_{A I T R} \mu_{\tilde{z}, t}+\mathbf{B}_{A I T R} \epsilon_{A I T R, t} \\
\mu_{\tilde{z}, t}=\tilde{\vartheta} \mu_{A I T R, t}+\mathbf{B}_{\tilde{z}} \epsilon_{\tilde{z}, t}
\end{gathered}
$$

where $\mu_{A I T R, t}$ and $\epsilon_{A I T R, t}$ are the reduced-form innovations and the structural shock on AITR, respectively, while $\mu_{\tilde{z}, t}$ and $\epsilon_{\tilde{z}, t}$ represent the reduced form innovations and the structural shocks of all other $\tilde{z}$ variables in our benchmark specification (12), i.e. all the variables in $z$ plus the ACTR. ${ }^{28}$ The matrices $\varrho_{A I T R}, \tilde{\vartheta}$, $\mathbf{B}_{A I T R}$, and $\mathbf{B}_{\tilde{z}}$ hold the structural coefficients of $\boldsymbol{\Gamma}$ introduced in (1), but with the current partition.

Similarly to the bechmark case, we estimate $\tilde{\vartheta}$ by using the narrative changes in income tax as instrument for $\mu_{A I T R, t}$. Once we have estimated $\tilde{\vartheta}$, we use $\left(\mu_{\tilde{z}, t}-\right.$ $\left.\vartheta \mu_{A I T R, t}\right)$ as instrument to estimate $\varrho_{A I T R}$. Then, the covariance of $\left(\mu_{A I T R, t}-\right.$ $\left.\varrho_{A I T R} \mu_{\tilde{z}, t}\right)$ can be used to estimate $\mathbf{B}_{A I T R} \mathbf{B}_{A I T R}^{\prime}$. Different to the benchmark case, these covariance restrictions are now sufficient to estimate all the elements in $\mathbf{B}_{A I T R}$.

${ }^{28}$ We apply the same partition, mutatis mutandis, for the case of ACTR. 
The underlying assumption behind this alternative specification is that the correlation between our narrative measures is random or solely due to measurement errors. In this way we can fully isolate the consequences of the joint identification scheme implemented in our benchmark specification. Figure 6 reports the effects on GDP resulting from the shocks in each tax component. For comparison we also report the IRFs of our benchmark case. Bounds are calculated as before.

GDP, ACTR Shock

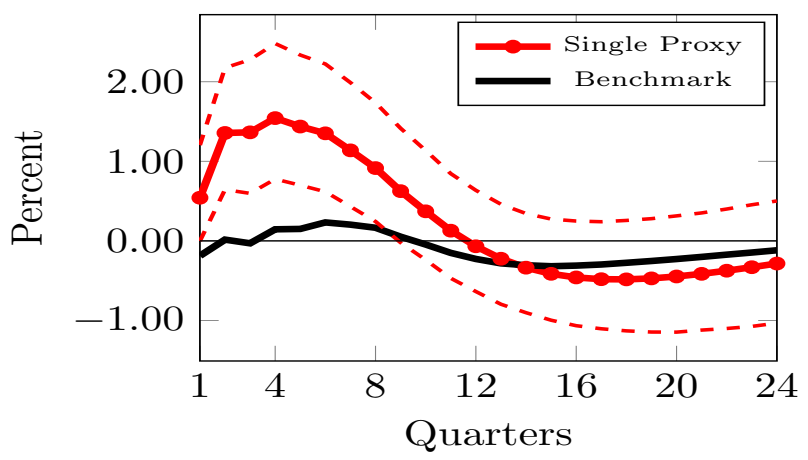

GDP, AITR Shock

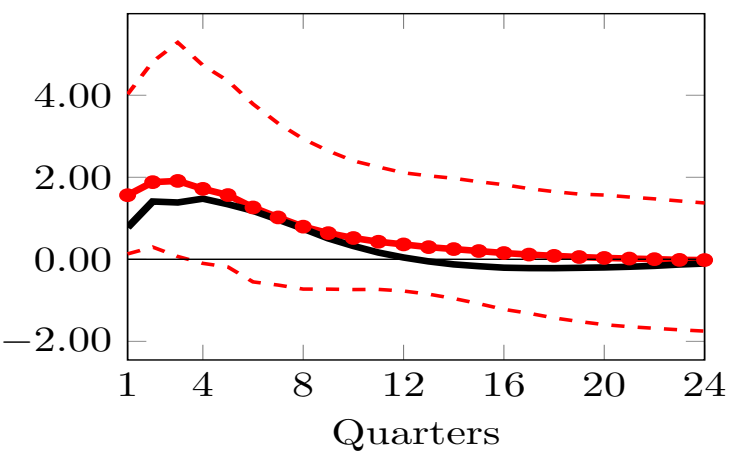

Figure 6. IRFs with Single Proxy Identification. Broken lines represent the 68 percent CONFIDENCE BOUNDS.

The key finding of this experiment is that one percentage point decrease in ACTR leads to a large and significant increase in GDP, with an impact response of 0.44 percent $(p=0.16)$ and a peak response of 1.5 percent $(p=0.07)$ in the fourth quarter, both significant at 68 percent. The implied maximal PVM of a one percentage point cut in ACTR is around 3, $\left(P V M_{\mathrm{GDP}}^{\max }=5.90\right)$ see Table 3. This outcome is in sharp contrast with the estimates obtained under our benchmark identification, where a shock to ACTR had only a modest and no significant effect on aggregate output. The sizeable difference obtained under the two approaches indicates that it is critical to control explicitly for the interactions between consumption and income tax components when measuring the effects of an ACTR shock. In different words, this means that the narrative liability changes in one tax component contains valuable information also about the shock to the other tax component.

This insight is particularly instructive because it enables us to understand the differences between our benchmark results and the ones presented in RieraCrichton, Vegh and Vuletin (2016), who find large and significant short run expansionary effects of consumption tax cuts but, as here, identify consumption tax shocks by only using narrative on consumption tax changes.

The estimates are somehow more similar to the benchmark identification for the case of AITR shocks. A one percentage point decrease in AITR results in a large and significant increase in GDP, with an impact response of around 1.5 percent 
$(p=0.15))$ and a peak response of 2 percent $(p=0.15)$ in the third quarter, both significant at 68 percent, and a maximal PVM of $3.39,\left(P V M_{\mathrm{GDP}}^{\max }=3.76\right)$ see Table 3. However the confidence bounds get larger with a single proxy approach. This suggests that a joint identification scheme of the two tax components is important also for the analysis of the transmission mechanism of income tax shocks.

\begin{tabular}{|c|c|c|c|c|c|c|c|}
\hline \multirow[b]{2}{*}{ Model } & \multicolumn{3}{|c|}{ AITR Shock } & \multicolumn{3}{|c|}{ ACTR Shock } & \multirow[b]{2}{*}{ Reliability } \\
\hline & Impact & $\mathbf{P V M} \mathbf{M}^{\max }$ & $\mathbf{P V M}_{\mathrm{GDP}}^{\max }$ & Impact & $\mathbf{P V M}^{\max }$ & $\mathbf{P V M}_{\mathrm{GDP}}^{\max }$ & \\
\hline Benchmark (Figures 2 and 3) & $0.78^{*}$ & $2.36^{*}$ & $2.62^{*}$ & -0.19 & 0.29 & 0.58 & $0.19,0.62$ \\
\hline Single Proxy (Figure 6) & $1.55^{*}$ & $3.39^{*}$ & $3.76^{*}$ & $0.44^{*}$ & $2.96^{*}$ & $5.90^{*}$ & $0.18,0.70$ \\
\hline Sign Restrictions (Figure 7) & $1.06^{* * *}$ & $3.31^{*}$ & $3.67^{*}$ & -0.27 & 0.11 & 0.22 & $0.27,0.85$ \\
\hline
\end{tabular}

The Sign-Restriction Approach. - As mentioned above, we rely on the exclusion restrictions (Cholesky) to identify the $\mathbf{B}_{\tau}$. For example, we assume that a shock to AITR is contemporaneously exogenous to ACTR. This assumption could be questioned as changes in these two components were often legislated at the same time.

In order to check the robustness of our benchmark results, we use an alternative identification procedure that does not suffer from this problem. This identification strategy is based on sign restriction, pioneered by Faust (1998), Canova and De Nicolo (2002) and Uhlig (2005) and more recently applied in the context of narratively identified SVARs by Piffer and Podstawski (2017), Antolín-Díaz and Rubio-Ramírez (2018) and Caldara and Herbst (2018). The advantage of this approach is that timing assumptions on the contemporaneous impact matrix of the shocks are not necessary. Instead, restrictions which are often used implicitly, consistent with the conventional view, are made more explicit. In this context, our identifying assumption is that a shock in one tax component correlates more, on impact, with variations in the corresponding tax rate. For example, a shock of income tax correlates more on impact with AITR than with ACTR. Note that this identification strategy is agnostic about the correlation between the narrative proxies and the shocks. In turn these correlations are estimated, as before, via (13) and (14).

Technically, we can describe our sign-restriction approach as follows. First, let 
us re-write the term in square brackets of equation (15) as follows:

$$
\left[\begin{array}{c}
\mathbf{I}+\varrho(\mathbf{I}-\vartheta \varrho)^{-1} \vartheta \\
(\mathbf{I}-\vartheta \varrho)^{-1} \vartheta
\end{array}\right]=\left[\begin{array}{cc}
a_{11} & a_{12} \\
a_{21} & a_{22} \\
\vdots & \vdots \\
a_{n 1} & a_{n 2}
\end{array}\right]
$$

where the parameters in the square bracket on the left-hand side are estimated as before. Second, instead of using a Cholesky decomposition of $\mathbf{B}_{\tau} \mathbf{B}_{\tau}^{\prime}=\Sigma$, we look for a matrix $\hat{\mathbf{B}}_{\tau}=\left[\begin{array}{ll}b_{11} & b_{12} \\ b_{21} & b_{22}\end{array}\right]$, such that $\hat{\mathbf{B}}_{\tau} \hat{\mathbf{B}}_{\tau}^{\prime}=\Sigma$ and that satisfies the following restrictions:

1) $a_{11} b_{11}+a_{12} b_{21}>0$

2) $a_{21} b_{12}+a_{22} b_{22}>0$

3) $\left|a_{11} b_{11}+a_{12} b_{21}\right|>\left|a_{21} b_{11}+a_{22} b_{21}\right|$;

4) $\left|a_{21} b_{12}+a_{22} b_{22}\right|>\left|a_{11} b_{12}+a_{12} b_{22}\right|$.

The first two conditions imply that a positive tax shock raises on impact its corresponding tax rate. The next two conditions are crucial for the proposed identification. Specifically, the third condition indicates that a consumption tax shock has a bigger effect on impact on ACTR than on AITR, while the fourth condition implies that an income tax shock has a bigger effect on impact on AITR than on ACTR.

We follow the standard approach in the literature on sign-identified VAR models and rely on Bayesian methods for inference. We set priors using dummy observations as in Banbura, Giannone and Reichlin (2010). Then, we apply a Gibbs sampling approach and draw $\hat{\mathbf{B}}_{\tau}$ in each iteration and only retain those that satisfy the aforementioned conditions.

It is important to note that our sign restriction approach relaxes the exclusion restriction of the recursively identified model presented in the benchmark, but it does so by imposing restrictions on other parameters that were previously unconstrained, i.e. the elements in $\hat{\mathbf{B}}_{\tau}$. As such, we gain generality in some dimensions and we lose it in others. In this respect, the two approaches can be considered as alternatives: while Cholesky represents a mechanical/statistical approach, sign restriction imposes more economic theory on the econometric model.

Figure 7 presents the posterior median and its 68 percent credible set. The main message of this experiment is that results under the sign-restriction identification scheme are consistent with our benchmark specification. A shock to ACTR is not significant on GDP on the 68 percent credibility set. Differently, a shock to AITR is expansionary with a maximal effect on the fifth quarter of 1.71 and 90 
percent credibility set $[0.68-4.23]$. We also find that the maximal PVM is 3.31 , $\left(P V M_{\mathrm{GDP}}^{\mathrm{max}}=3.67\right)$ see Table 3.

Finally, and consistent with the benchmark results, we find that changing the composition of taxes from income to consumption through a revenue neutral policy is expansionary.

GDP, ACTR Shock

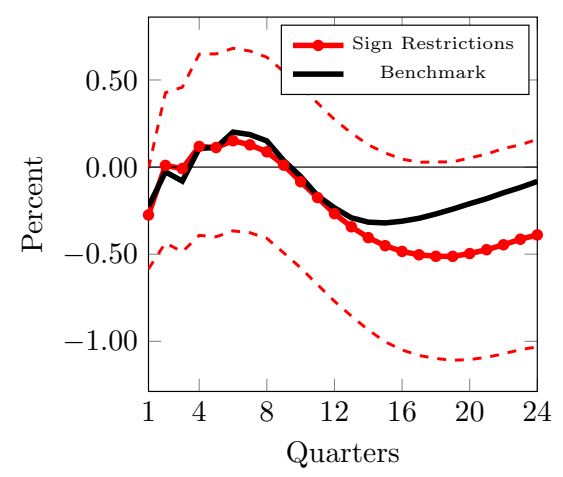

GDP, AITR Shock

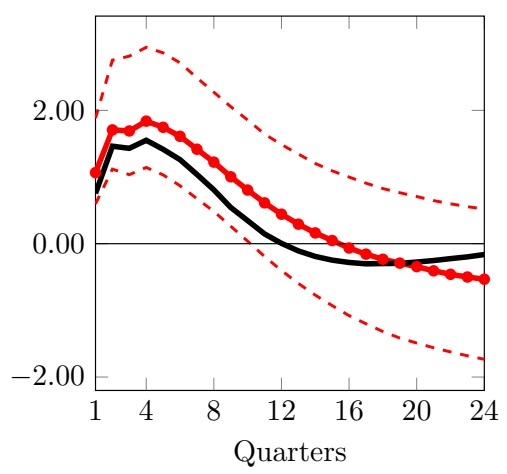

GDP, Rev. Neutral

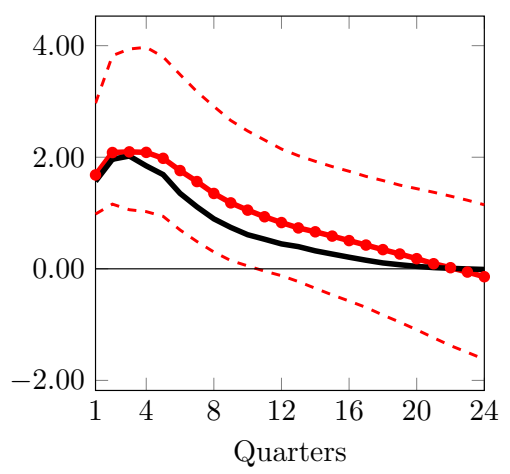

Figure 7. IRFs and Revenue Neutral Experiment with Sign-Restrictions Identification. BroKEN LINES REPRESENT THE 68 PERCENT CREDIBILITY SET.

\section{Conclusions}

We analyse the aggregate effects of unexpected changes in consumption and income taxes in the United Kingdom for the period 1973-2009. We estimate 'ProxySVARs' by using narratively identified tax changes in income and consumption taxes as proxies for the latent structural tax shocks. We present two important set of results. First, we find important differences in the size and the significance of the two tax multipliers. The short run effects of income tax changes are large, significant and persistent on output, private consumption and investment. On the same variables, consumption tax changes have effects that are modest and in most cases, not statistically different from zero. Second we find that changing the composition of taxes from income to consumption is expansionary.

These results have several important implications. First, they show that it is crucial to distinguish between direct and indirect taxation when studying the transmission mechanism of fiscal policy as changes in these two tax categories have very different effects on key macroeconomic variables. Analyses that focus exclusively on changes in total tax revenues generally miss these insights and therefore they can offer only a limited perspective in the relative benefits of different tax components. Second, our results provide empirical insights for the fiscal reforms legislated in the UK over the period 1979-1997 where cuts of income based taxation were coupled with increases in consumption taxation. Third our 
results represent an empirical test for the theoretical predictions of conventional public finance theories, where consumption taxes are found to be less distortive than income taxes.

An important limit of our analysis is that we analyse two broad tax categories. For example, our definition of income taxation aggregates changes in personal and corporate taxes. This is due to data limitation. As a consequence, our approach may mask some important differences in the transmission mechanism of distinct tax components that are now aggregated into income tax. For example, while both personal and corporate tax cuts are expansionary on GDP, their short-run effects are likely to be different on private consumption and the labour market, see Mertens and Ravn (2013). When more data on fiscal revenues becomes available, it will be possible to study the effects of each narrowly defined tax categories in isolation.

There are several important avenues for future research. First, it would be interesting to extend our analysis on the effects of income and consumption taxation for different income groups as in Mertens and Montiel-Olea (2018) or by grouping consumers by housing tenure as in Cloyne and Surico (2017). Second, it would be interesting to allow for time-varying effects of tax shocks in the vein of Auerbach and Gorodnichenko (2012) and Ramey and Zubairy (2014). In this way one could check whether the transmission mechanism of consumption and income taxation is different in good and in bad times or when the nominal interest rate is close to its zero lower bound. Third, our dataset allows to analyse the effects of tax uncertainty on the economy, thus extending on the fiscal dimension the recent literature on volatility shocks, e.g. Giovanni Caggiano, Efrem Castelnuovo and Nicolas Groshenny (2014) and Mumtaz and Theodoridis (2016). Finally, our sign restriction identification scheme could be applied in different contexts, such as for monetary policy analysis, along the line of Caldara and Herbst (2018).

\section{REFERENCES}

Altig, David, Alan J. Auerbach, Laurence J. Koltikoff, Kent A. Smetters, and Jan Walliser. 2001. "Simulating Fundamental Tax Reform in the United States." American Economic Review, 91(3): 574-595.

Antolín-Díaz, Juan, and Juan F Rubio-Ramírez. 2018. "Narrative sign restrictions for SVARs." American Economic Review, 108(10): 2802-29.

Auerbach, Alan J., and Yuriy Gorodnichenko. 2012. "Measuring the Output Responses to Fiscal Policy." American Economic Journal: Economic Policy, 4(2): 1-27.

Auerbach, Alan J., Laurence J. Kotlikoff, and Jonathan Skinner. 1983. "The Efficiency Gains from Dynamic Tax Reform." International Economic Review, 24(1): pp. 81-100. 
Banbura, Marta, Domenico Giannone, and Lucrezia Reichlin. 2010. "Large Bayesian vector auto regressions." Journal of Applied Econometrics, 25(1): 71-92.

Barro, Robert J., and Charles J. Redlick. 2011. "Macroeconomic Effects From Government Purchases and Taxes." The Quarterly Journal of Economics, 126(1): 51-102.

BIS. 2015. "Nominal effective exchange rate Dataset." https: //www. bis . org/ statistics/eer. htm.

Blanchard, Olivier, and Roberto Perotti. 2002. "An Empirical Characterization of the Dynamic Effects of Changes in Government Spending and Taxes on Output." The Quarterly Journal of Economics, 117(4): 1329-1368.

Brüggemann, Ralf, Carsten Jentsch, and Carsten Trenkler. 2016. "Inference in VARs with conditional heteroskedasticity of unknown form." Journal of Econometrics, 191(1): $69-85$.

Caggiano, Giovanni, Efrem Castelnuovo, and Nicolas Groshenny. 2014. "Uncertainty shocks and unemployment dynamics in U.S. recessions." Journal of Monetary Economics, 67: 78 - 92 .

Caldara, Dario, and Christophe Kamps. 2017. "The Analytics of SVARs: A Unified Framework to Measure Fiscal Multipliers." The Review of Economic Studies.

Caldara, Dario, and Edward Herbst. 2018. "Monetary policy, real activity, and credit spreads: Evidence from bayesian proxy svars." American Economic Journal: Macroeconomics.

Canova, Fabio, and Gianni De Nicolo. 2002. "Monetary disturbances matter for business fluctuations in the G-7." Journal of Monetary Economics, 49(6): 1131-1159.

Cloyne, James. 2012. "Discretionary tax shocks in the United Kingdom 19452009: a narrative account and dataset." MPRA Working Paper 37739.

Cloyne, James. 2013a. "Discretionary Tax Changes and the Macroeconomy: New Narrative Evidence from the United Kingdom." American Economic Review, 103(4): 1507-28.

Cloyne, James. 2013b. "Narrative Dataset for Discretionary Tax Changes and the Macroeconomy: New Narrative Evidence from the United Kingdom." https: //drive. google. com/file/d/OBOHi1TiBB5rRQU9lWWJJR2F3RmM/ view. 
Cloyne, James S., and Paolo Surico. 2017. "Household Debt and the Dynamic Effects of Income Tax Changes." Review of Economic Studies, 84(1): 4581.

Coleman, Wilbur John II. 2000. "Welfare and Optimum Dynamic Taxation of Consumption and Income." Journal of Public Economics, 76(1): 1-39.

Correia, Isabel. 2010. "Consumption Taxes and Redistribution." American Economic Review, 100(4): 1673-1694.

Farhi, Emmanuel, Gita Gopinath, and Oleg Itskhoki. 2014. "Fiscal Devaluations." Review of Economic Studies, 81(2): 725-760.

Faust, Jon. 1998. "The robustness of identified VAR conclusions about money." Vol. 49, 207-244, Elsevier.

Favero, Carlo, and Francesco Giavazzi. 2012. "Measuring Tax Multipliers: The Narrative Method in Fiscal VARs." American Economic Journal: Economic Policy, 4(2): 69-94.

Fernández-Villaverde, Jesús. 2010. "Fiscal Policy in a Model with Financial Frictions." American Economic Review, 100(2): 35-40.

FRED. 2015. "Data: 3-Month or 90-day Rates and Yields: Treasury Securities for the United Kingdom." https: // research. stlouisfed. org/fred2/ series/IR3TTSO1GBM156N.

HMRC. 2016a. "HM Revenue and Customs: Air Passenger Duty Bulletin." https: //www. uktradeinfo. com/Statistics/StatisticalBulletins/ Pages /BulletinArchive. aspx? viewname $=$ Air $\backslash \% 20$ Passenger $\backslash \% 20 D u t y \backslash$ $\%$ 20Archive.

HMRC. 2016b. "HM Revenue and Customs: Betting and Gaming Bulletin." https: //www. uktradeinfo. com/Statistics/StatisticalBulletins/ Pages/BulletinArchive. aspx? viewname=Betting $\ \%$ 2c \\%20Gaming $\backslash$ $\% 20$ and $\backslash \% 20$ Lottery $\ \% 20 D$ uties $\ \% 20$ Archive.

HMRC. 2016c. "HM Revenue and Customs: Insurance Premium Tax Bulletin." https: //www. uktradeinfo. com/Statistics/StatisticalBulletins/ Pages/BulletinArchive. aspx? viewname=Insurance $\mid \% 20$ Premium $\mid$ \%20Tax \\%20Archive.

Hussain, Syed M, and Lin Liu. 2018. "Comparing the effects of discretionary tax changes between the US and the UK." The BE Journal of Macroeconomics, 18(1).

Jentsch, Carsten, and Kurt Lunsford. 2018. "The Dynamic Effects of Personal and Corporate Income Tax Changes in the United States: Comment." The American Economic Review. 
Jones, Larry E., Rodolfo E. Manuelli, and Peter E. Rossi. 1993. "Optimal Taxation in Models of Endogenous Growth." Journal of Political Economy, 101(3): pp. 485-517.

Leeper, Eric M. 1991. "Equilibria under 'active' and 'passive' monetary and fiscal policies." Journal of Monetary Economics, 27(1): 129-147.

Mertens, Karel, and Jose Luis Montiel-Olea. 2018. "Marginal Tax Rates and Income: New Time Series Evidence." Quarterly Journal of Economics, 133(4): 1803-1884.

Mertens, Karel, and Morten O. Ravn. 2012. "Empirical Evidence on the Aggregate Effects of Anticipated and Unanticipated US Tax Policy Shocks." American Economic Journal: Economic Policy, 4(2): 145-81.

Mertens, Karel, and Morten O. Ravn. 2013. "The Dynamic Effects of Personal and Corporate Income Tax Changes in the United States." American Economic Review, 103(4): 1212-47.

Mertens, Karel, and Morten O. Ravn. 2014. "A reconciliation of SVAR and narrative estimates of tax multipliers." Journal of Monetary Economics, 68(S): S1-S19.

Mertens, Karel, and Morten Ravn. 2018. "The Dynamic Effects of Personal and Corporate Income Tax Changes in the United States: Reply to Jentsch and Lunsford."

Montiel-Olea, José Luis, James H Stock, and Mark W Watson. 2017. "Inference in structural VARs with external instruments."

Mountford, Andrew, and Harald Uhlig. 2009. "What are the effects of fiscal policy shocks?" Journal of Applied Econometrics, 24(6): 960-992.

Mumtaz, Haroon, and Konstantinos Theodoridis. 2016. "The changing transmission of uncertainty shocks in the US: An empirical analysis." Journal of Business \& Economic Statistics, 0(ja): 1-39.

Nevo, Aviv, and Adam M. Rosen. 2012. "Identification With Imperfect Instruments." The Review of Economics and Statistics, 94(3): 659-671.

Newey, WK, and KD West. 1987. "A simple, positive semi-definite, heteroskedasticity and autocorrelation consistent covariance matrix." Econometrica, 55(3): 703-708.

ONS. 2016a. "Labour market statistics time series Dataset." https: //www. ons. gov. uk/employmentandlabourmarket/peopleinwork/ employmentandemployeetypes/datasets/labourmarketstatistics. 
VOL. VOL NO. ISSUE THE EFFECTS OF INCOME AND CONSUMPTION TAX CHANGES 33

ONS. 2016b. "Public Sector Finances Borrowing By SubSector Datatset." https://www. ons.gov. uk/economy/ governmentpublicsectorandtaxes/publicsectorfinance/datasets/ publicsectorfinancesborrowingbysubsector.

ONS. 2016c. "Public Sector Finances Time Series Datatset." https: //www. ons. gov. uk/ economy/governmentpublicsectorandtaxes/ publicsectorfinance/datasets/publicsectorfinances.

ONS. 2016d. "UK Economic Accounts Time Series Dataset." https: //www. ons. gov. uk/economy/grossdomesticproductgdp/datasets/ unitedkingdomeconomicaccounts.

Peersman, Gert. 2005. "What caused the early millennium slowdown? Evidence based on vector autoregressions." Journal of Applied Econometrics, 20(2): 185-207.

Piffer, Michele, and Maximilian Podstawski. 2017. "Identifying Uncertainty Shocks Using the Price of Gold." The Economic Journal.

Ramey, Valerie A., and Sarah Zubairy. 2014. "Government Spending Multipliers in Good Times and in Bad: Evidence from U.S. Historical Data." National Bureau of Economic Research, Inc NBER Working Papers 20719.

Riera-Crichton, Daniel, Carlos A. Vegh, and Guillermo Vuletin. 2016. "Tax multipliers: Pitfalls in measurement and identification." Journal of Monetary Economics, 79: 30 - 48.

Romer, Christina D., and David H. Romer. 2009. "Do Tax Cuts Starve the Beast? The Effect of Tax Changes on Government Spending." Brookings Papers on Economic Activity, 40(1 (Spring): 139-214.

Romer, Christina D., and David H. Romer. 2010. "The Macroeconomic Effects of Tax Changes: Estimates Based on a New Measure of Fiscal Shocks." American Economic Review, 100(3): 763-801.

Sims, Eric, and Jonathan Wolff. 2018. "The state-dependent effects of tax shocks." European Economic Review, 107: 57 - 85.

Stock, James H., and Mark W. Watson. 2012. "Disentangling the Channels of the 2007-2009 Recession." National Bureau of Economic Research Working Paper 18094.

Stock, James H., and Mark W. Watson. 2018. "Identification and Estimation of Dynamic Causal Effects in Macroeconomics Using External Instruments." The Economic Journal, 128(610): 917-948.

Summers, Lawrence H. 1981. "Capital Taxation and Accumulation in a Life Cycle Growth Model." American Economic Review, 71(4): 533-44. 
Trabandt, Mathias, and Harald Uhlig. 2011. "The Laffer curve revisited." Journal of Monetary Economics, 58(4): 305-327.

Trabandt, Mathias, and Harald Uhlig. 2012. "How Do Laffer Curves Differ across Countries?" In Fiscal Policy after the Financial Crisis. NBER Chapters, 211-249. National Bureau of Economic Research, Inc.

Uhlig, Harald. 2005. "What are the effects of monetary policy on output? Results from an agnostic identification procedure." Journal of Monetary Economics, 52(2): 381-419.

Woodford, Michael. 1995. "Price-level determinacy without control of a monetary aggregate." Carnegie-Rochester Conference Series on Public Policy, 43: 1 -46 .

Zidar, Owen. 2018. "Tax Cuts for Whom? Heterogeneous Effects of Tax Changes on Growth and Employment." Journal of Political Economy. 